\title{
Development of hybrid steel-basalt fiber reinforced concrete - in aspects of flexure, fracture and microstructure
}

\author{
J. Vinotha Jenifer (Main Author and Corresponding Author) \\ Thiagarajar College of Engineering, Department of Civil Engineering \\ 625015, Madurai (India) \\ vinothajenifer@gmail.com \\ D. Brindha \\ Thiagarajar College of Engineering, Department of Civil Engineering \\ 625015, Madurai (India) \\ dbciv@tce.edu \\ Manuscript Code: 14268 \\ Date of Acceptance/Reception: 05.03.2021/19.05.2020 \\ DOI: $10.7764 /$ RDLC.20.1.62
}

\begin{abstract}
The conventional concrete is considered to be critical in various constructional applications due to its setbacks such as service load failures, brittle property, low ductility and low tensile capacity. Apart from the natural bridging mechanism (aggregate bridging), an additional bridging mechanism is necessary to overcome the existing setbacks in plain cement concrete. Thus concrete with one or more types of fibers in suitable combinations can augment the mechanical performance of concrete causing a positive synergy effect. Along with the two control mixes with and without copper slag as partial replacement of fine aggregate, two different groups of hybrid combination of fibers such as steel and basalt were cast with 3 different groups of coarse aggregate proportions of sizes $20 \mathrm{~mm}$ and $12.5 \mathrm{~mm}$. The hybridization of fibers is assessed in this study under compression, tension, flexure and fracture. Stress-strain data were recorded under compression to validate the strain capacity of the mixtures. The mechanical properties were analyzed for the positive hybrid effect and the influencing factors were copper slag, hybrid fiber combination and coarse aggregate proportions. The optimum volume fraction of fibers and mix proportions were highlighted based on various behaviors of concrete. Steel as macro fibers and basalt as microfibers were examined under microstructural studies (SEM and EDX). The results from the flexural toughness showcased the potential of hybrid fibers with greater energy absorption capacity ensuring the ductile property of the proposed hybrid fiber reinforced concrete.
\end{abstract}

Keywords: hybridization, copper slag, steel fibers, basalt fibers, fracture, toughness, SEM, EDX.

Concrete has been a widespread construction material with extensive applicability for its various advantages. However, concrete has its weaknesses such as low tensile strength, low strain capacity, inadequate resistance to crack growth, etc. (Li, Chi, Xu, Shi, \& Li, 2018). Augmentation of ductility in concrete is the need of the hour. Integrating fiber with concrete incapacitates the weakness of the material characteristics, bids better solution enhancing strength and ductility of concrete by functioning during crack formation (Sun, Hao, Zhao, Wu, \& Yang, 2018; Wang, Ju, Shen, \& Xu, 2019,Alex, 2019; Karahan, 2020). The internal or external stress deforms the matrix and it transfers the stresses to fibers. The randomly dispersed fibers delay the crack initiation and propagation due to their stress transfer capability (Bentur \& Mindess, 2007). While the mono-fiber reinforcement in concrete ensures random dispersion of fibers arresting crack zones with only one type of fiber, the concrete demands multi-level reinforcement with unconstrained range of strains. To meet the multi-scale fracture characteristics of concrete, different types of fibers with diverse intrinsic responses, shape, size and function must be integrated.

The resulting hybridization in concrete is termed as hybrid fiber reinforced concrete (HFRC) (Banthia, Majdzadeh, Wu, \& Bindiganavile, 2014; Cattaneo \& Biolzi, 2010; Teng, Afroughsabet, \& Ostertag, 2018). The diverse nature of fibers, rationally fused in the concrete is capable of providing resistance to cracking at multi-scale levels depending on the individual property of fiber (Banthia et al., 2014). Published investigations on HFRC with several types of fibers are tabulated as a summary in Table 1 . The collection of research work showcases the necessity of multi-level reinforcement to counteract the setbacks in concrete. There is a limited understanding of choosing the optimum combination of fibers that can provide a positive synergy effect in the performance of concrete. The majority of the investigations integrated steel as micro or macro fibers along with other non-metallic fibers due to the predominant property of steel fibers(Banthia et al., 2014; Chun \& Yoo, 2018; Guler, 2019; Li et al., 2018; C. X. Qian \& Stroeven, 2000; Sahoo, et al., 2014).

From the observed works of literature, it is found to be no alternative to substitute the performance of steel fibers (Abbass, Khan, \& Mourad, 2018; Holschemacher, Mueller, \& Ribakov, 2010; Nataraja, 1999; Saidani, Saraireh, \& Gerges, 2016; Yap, Alengaram, \& Jumaat, 2015). In addition to steel fibers, natural fibers are the current deal of interest. 
Synthetic fibers are quite expensive and consume extensive energy for their production process. Focusing on the concept of utilizing globally available material, low modulus natural mineral fibers can be of greater advantage in the case of HFRC. The limited investigations on the natural mineral fibers in hybrid combination with metallic fibers demand much more attention to assess the performance of HFRC for its distinctive properties.

Basalt is a natural mineral fiber processed and acquired from volcanic rocks. Being the non-polluting natural fiber for its recycling ability, it has superior resistance to elevated temperatures and explosions. Its energy absorption characteristics and bond performance are substantial (Erden \& Ho, 2017; Taylor \& Jamshaid, 2015). The fibers are incorporated from the length of $9 \mathrm{~mm}$ to $50 \mathrm{~mm}$ with a diameter between $9-22 \mu \mathrm{m}$ in discrete form. Over decades, researchers claim to obtain elevated mechanical properties up to the volume fraction of $2 \%$ to the total volume of concrete between the length of about 6-36 mm and diameter of 10-25 $\mu \mathrm{m}$ (Ayub \& Khan, 2017; Ayub, Shafiq, \& Nuruddin, 2014; Shafiq, Ayub, \& Ullah, 2016; Sruthi Jalasutram, Dipti Ranjan Sahoo, 2016).

Investigators obtained pronounced results on the mechanical behavior of basalt fiber reinforced concrete at the watercement ratio between 0.4 to 0.6 (Branston, Das, Kenno, \& Taylor, 2016; Jiang, Fan, Wu, \& Chen, 2014; Kizilkanat, Kabay, Akyüncü, Chowdhury, \& Akça, 2015; Sruthi Jalasutram, Dipti Ranjan Sahoo, 2016). Basalt as microfibers has its potential advantages to complement steel fibers. Hua Zhang et al., examined the mechanical properties of the micro hybrid fibers (steel and basalt) by using detritus as coarse aggregate and established noticeable strength (H. Zhang, Wang, Bai, Addae, \& Neupane, 2019) under static and dynamic loading conditions. Dehong wang et al., (Wang et al., 2019) observed both positive and negative synergy effect for the combination of polypropylene and basalt fibers as micro fibers under mechanical properties. The fibers chosen for the study satisfies the key aspects of hybridization. One fiber complements the other with its individual significant properties. Thus the micro fibers (basalt fibers) are chosen as strong and stiffer to function at initial crack stress whereas macro fibers (steel fibers) are opted to be flexible and ductile for its toughness quality.

Before the initiation of cracks and the fiber starts to act, the performance of the concrete solely depends on the quality of the matrix. While adopting hybrid fibers, the greater concern is water demand. To stabilize the matrix with lesser water content, a sustainable material as fine aggregate has been adopted. Copper slag, a non-hazardous residue obtained from the copper smelters which is dominant in Iron, silica, aluminium oxides, etc. (Murari, Siddique, \& Jain, 2014; R. Tixier, R. Devaguptapu, 1997; Shi, Meyer, \& Behnood, 2008). The glassy appearance of the grain yields lower water absorption capacity enhancing the working condition of the concrete. Among various industrial wastes, copper slag is considered to perform better under strength and durability characteristics when it is replaced with $40 \%$ for fine aggregate (Al-Jabri, Al-Saidy, \& Taha, 2011; Kumar, Kumar, \& Kumar, 2016; Wu, Zhang, \& Ma, 2010). Researchers also integrated copper slag with mono fibers such as steel, polypropylene showcases predominant results compared to conventional fiber reinforced concrete (FRC) (Chakrawarthi et al., 2016; John, Vinotha Jenifer, 2019).

The hybrid combination of steel and basalt fibers along with copper slag can produce complementary advantages to each other in the matrix. Moreover, previous researches had limited focus on examining the influence of fine and coarse aggregate in the mechanical performance of HFRC. The present study was carried out to assess the performance of integrated steel and basalt fibers in Hybrid form for their load carrying capacity and fracture mechanisms. Examination on the influence of coarse and fine aggregate has also been performed to ensure the distinct property of concrete. Microstructural investigations have been undertaken to relate the bond performance of the Interfacial transition zone to the matrix and to identify the chemical composition influencing the strength parameters of the mixture using Scanning Electron Microscopy (SEM) and Energy Dispersive X-ray Analysis (EDAX). 
Author Ref

(Banthia et al., 2014)

(Teng et al., 2018)

(Sun et al., 2018)

(Sahoo et al., 2014)

(Li et al., 2018)

(Correal, Herrán, Carrillo, Reyes, \& Hermida, 2018)

(Chun \& Yoo, 2018)

(Bhosale, Rasheed, Prakash, \& Raju, 2019)

(Koniki \& Prasad, 2019)

(H. Zhang et al., 2019)

(C. Qian \& Stroeven, 2000)

(Cao, Xie, \& Guan, 2019)

(Cattaneo \& Biolzi, 2010)

(Dawood, Mohammad, Abbas,

\& Mannan, 2018)

(Afroughsabet et al., 2018)

(Engineering \& Planning,

2012)

(Building, 1975)

(Yurtseven, Yaman, \& Tokyay, 2006)

(Guler, 2019)

(Mobasher, Yao, \&

Soranakom, 2015)

(Wang et al., 2019)
Hybrid Fibers material

steel, cellulose

steel, polyvinyl alcoho

steel, polyvinyl alcoho

steel, polypropylene

steel (straight, hooked end, corrugated), polypropylene steel (SF), polyethylene (PF)

ateel (micro, macro, hooked, twisted)

steel, polyolefin

steel, polyester, polypropylene steel, basalt

steel, polypropylene

polyvinyl alcohol, steel, $\mathrm{CaCO}_{3}$ whiskers carbon, polypropylene, steel

carbon, polypropylene

steel, polyvinyl alcoho

wire fiber, mill cut fiber, polypropylene

nylon, polypropylene, glass, asbestos, carbon

steel, polypropylene

steel, polyamide

alumina, carbon,

polypropylene

steel, basalt, polypropylene Findings

Hybrid effect showcased enhance performance under flexure and toughness

Hybridization improved the flexural properties unlike tension and compression

Compressive toughness, ductility and strain behavior had better development compared to the elastic modulus

The hybrid combination boosts displacement ductility, post-peak residual strength and strain-hardening response whereas reduction in peak load resistance of RC beams was observed

Positive synergy effect on first cracking properties, post-peak ductility and at the pre-peak stage. Compared to hooked end steel mono-fibers, twisted - hooked end fibers showed better failure behavior than straight steel fibers.

Hybrid fiber ratio (PF/SF) equals 2.0 had lower residual strengths compared to the ratio less than or equal to 1.5 . Recommended hybrid fiber ratio for the application of thin concrete walls for low-rise housing is given by 1 to 1.5 .

The combination of macro straight and microfibers increased
form enhanced the post cracking tensile strength of concrete.

The hybridization effect improvised the residual strength at the smaller crack opening. The fracture process zone is found to be less distributed in synthetic FRC compared to Steel FRC and hybrid form.

Non-metallic hybrid fibers showcased heightened mechanical properties. Positive synergy effect observed for the hybrid form of metallic and non-metallic fibers predominantly during crack control stages.

Strength increment of about $35 \%$ was observed under static loading conditions. The hybrid effect boosted toughness and impact strength. SHPB test examined the concrete as a strain-rate sensitive combination.

The hybrid combination influences load-bearing capacity in a small displacement range with the larger length of steel fibers. A positive effect on fracture toughness was observed.

At the microscale level, $\mathrm{CaCO}_{3}$ whiskers arrested cracks enhancing fracture toughness compared to steel and PVA fibers. Adopted hybridization ensures multi-scale resistance to cracking

Polypropylene fibers with other hybrid fibers create a negative effect on the performance of concrete under elevated temperature.

Hybridization enhanced flexural toughness compared to individual fibers in foamed concrete.

A positive synergy effect was observed in the deflection hardening response for all the combinations. A reduction in shrinkage deformation was noticed.

Improvement in bending and tensile strength along with heightened impact resistance ability was established

The hybrid combination is capable of augmenting the tensile and bending properties.

The combination enhanced the ultimate failure strength but the synergetic response was not observed in flexural toughness or ductility.

Notable tensile and flexural strength was observed

Enhancement in peak load up to $75 \%$ was established in the hybrid combination compared to individual performance of polypropylene fibers.

Positive results was observed for the hybrid combination of basalt and polypropylene under mechanical properties. 


\section{Materials and mixtures}

Two types of fibers - steel and basalt were used as shown in Table 2. The steel fibers were hooked end macro fiber to provide anchorage for the bridging mechanism and create pull-out resistance. The basalt fibers were straight and microfiber for their ability to act at the micro and meso level crack formation shown in fig 1(a). Upon mixing, steel fibers fig 1 (b) are hydrophobic in nature, do not absorb water, sticks to the matrix due to the hooked end geometry of the fiber. The voids created between the fiber and the matrix is stabilized by the basalt fibers which are hydrophilic in nature absorbs water while mixing and disperses numerous micro strands into the mixture. The excess water demand for the basalt fibers is compensated by the water bled from copper slag which absorbs a negligible amount of water while mixing.

Pozzolana portland cement as binder material with density of $3.05 \mathrm{~g} / \mathrm{cm}^{3}$ conforming IS 1489.1.1991, river sand with specific gravity of 2.5 and Copper slag with the specific gravity of 3.5 as fine aggregate as per IS 383.1970, Coarse aggregate with the density of $2.7 \mathrm{~g} / \mathrm{cm}^{3}$ of size $12.5 \mathrm{~mm}$ and $20 \mathrm{~mm}$ were used. The water to cement ratio was adopted as 0.35 . To maintain the workability of the concrete, a polycarboxylic-based ether - masterglenium sky 8233 with the specific gravity of 1.08 has been used as a super plasticizer.

There were 12 concrete mixtures - six plain control concrete and six fiber reinforced concrete tabulated in Table 3 as per IS 10262-2009. The abbreviation used for the mixtures is based on the content of copper slag as $0 \%$ and $40 \%$, the volume fraction of fibers and aggregate proportion ( $A-100 \%$ of $20 \mathrm{~mm}, \mathrm{~B}-50 \%$ of $12.5 \mathrm{~mm}$ and $50 \%$ of $20 \mathrm{~mm}, \mathrm{C}-$ $100 \%$ of $12.5 \mathrm{~mm}$ ). The proportions of coarse aggregate in the mixtures are shown in Fig 2 . The volume fraction of steel fibers was fixed as $1.5 \%$ based on a previous study performed (John \& Vinotha Jenifer, 2019). The basalt fibers with copper slag showcased prominent results in the volume fraction of $0.6 \%$ and $2 \%$ under mechanical properties by various trial and error mixtures.

\begin{tabular}{|c|c|c|c|c|c|c|c|c|}
\hline Fiber & Picture & Type & $\begin{array}{l}\text { Length } \\
(\mathrm{mm})\end{array}$ & $\begin{array}{c}\text { Diameter } \\
(\mathrm{mm})\end{array}$ & $\begin{array}{l}\text { Young's } \\
\text { modulus } \\
(\mathrm{GPa})\end{array}$ & $\begin{array}{l}\text { Tensile } \\
\text { Strength } \\
\text { (MPa) }\end{array}$ & $\begin{array}{l}\text { Density } \\
\left(\mathrm{kg} / \mathrm{m}^{3}\right)\end{array}$ & $\begin{array}{c}\text { Aspect } \\
\text { ratio }\end{array}$ \\
\hline Steel & 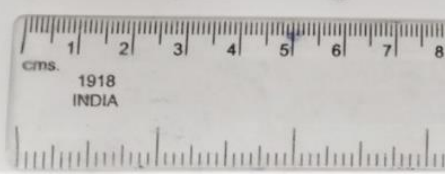 & $\begin{array}{c}\text { Hooked } \\
\text { end }\end{array}$ & 60 & 0.75 & 210 & 1100 & 7850 & 80 \\
\hline Basalt & 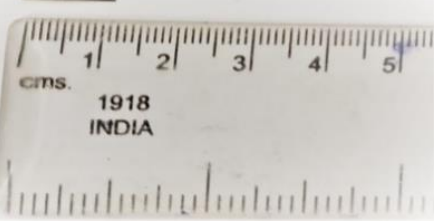 & Straight & $12-14$ & 0.025 & 89 & 4840 & 2700 & 480 \\
\hline
\end{tabular}

Figure 1. a) Basalt fibers; b) steel fibers. (Self-Elaboration).

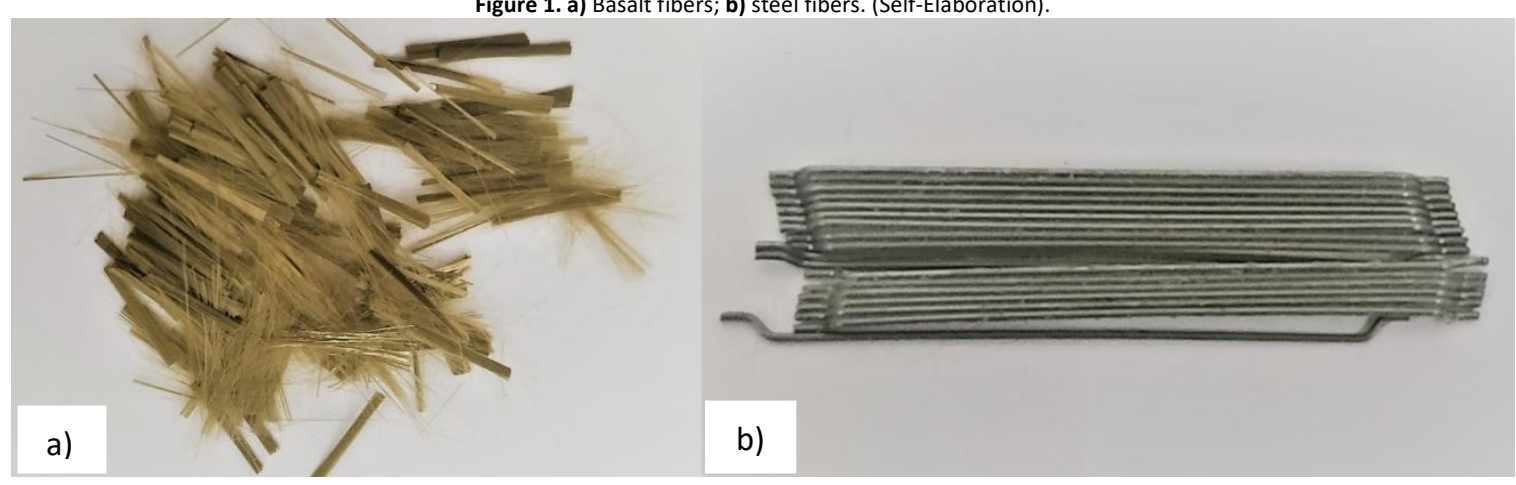


Figure 1. Proportions of coarse aggregate in mixtures. (Self-Elaboration).

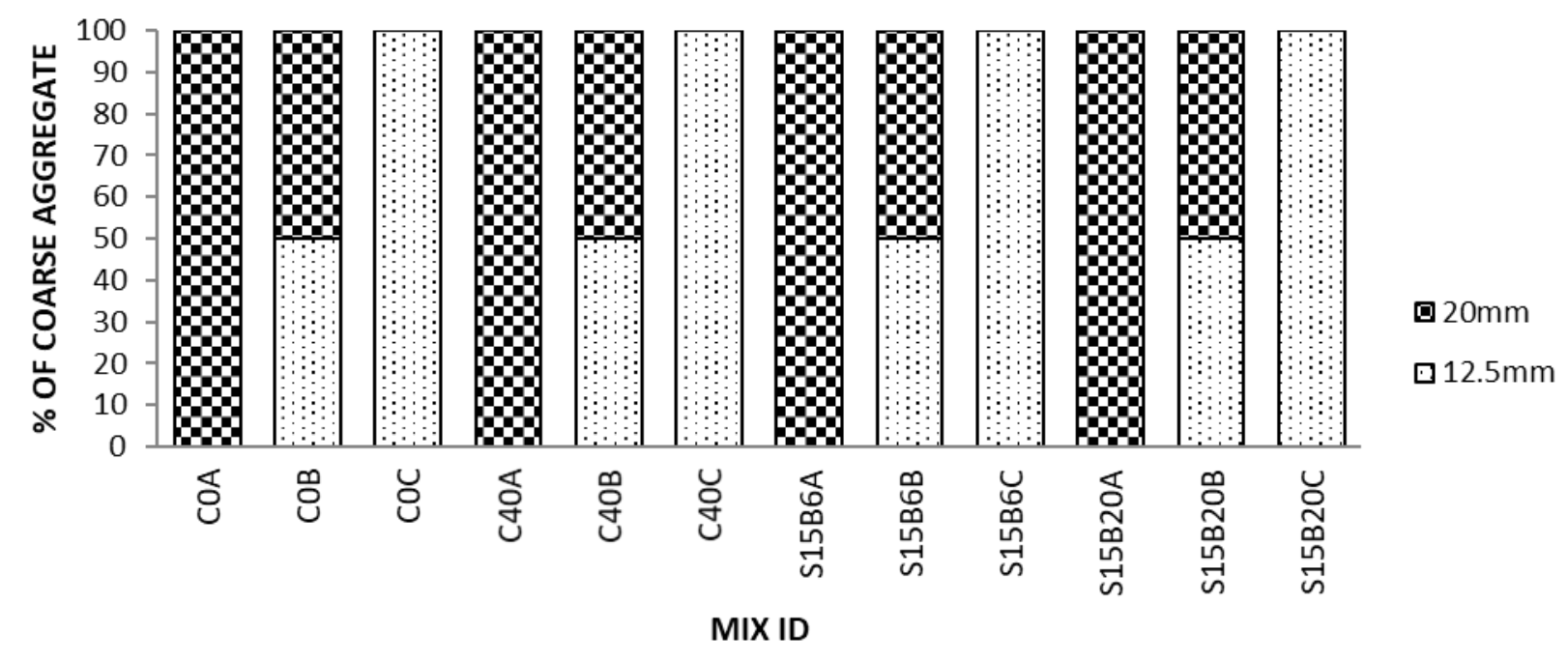

Table 1. Mix proportions. (Self-Elaboration).

\begin{tabular}{|c|c|c|c|c|c|c|c|c|c|c|}
\hline Mixture & & $\begin{array}{l}\text { Cement } \\
(\mathrm{kg})\end{array}$ & $\begin{array}{c}\text { River } \\
\text { sand (kg) }\end{array}$ & $\begin{array}{l}\text { Copper } \\
\text { slag (kg) }\end{array}$ & \multicolumn{2}{|c|}{$\begin{array}{c}\text { Coarse aggregate } \\
(\mathrm{kg})\end{array}$} & $\begin{array}{l}\text { Water } \\
(\mathrm{kg})\end{array}$ & $\begin{array}{c}\text { Super } \\
\text { plasticizer } \\
(\mathrm{kg})\end{array}$ & $\begin{array}{c}\text { Steel fibers } \\
\qquad\left(\% V_{f}\right)\end{array}$ & $\begin{array}{c}\text { Basalt fibers } \\
\left(\% V_{f}\right)\end{array}$ \\
\hline \multirow{3}{*}{$\mathrm{CO}$} & $A$ & 423 & 731 & - & - & 1128 & 148 & 2115 & - & - \\
\hline & B & 423 & 731 & - & 564 & 564 & 148 & 2.115 & - & - \\
\hline & C & 450 & 709 & - & 1093 & - & 161 & 2.115 & - & - \\
\hline \multirow{3}{*}{ C40 } & $A$ & 423 & 438 & 409 & - & 1128 & 148 & 2.115 & - & - \\
\hline & B & 423 & 438 & 409 & 564 & 564 & 148 & 2.115 & - & - \\
\hline & C & 450 & 425 & 396 & 1093 & - & 161 & 2.115 & - & - \\
\hline \multirow{3}{*}{ S15B6 } & A & 423 & 438 & 409 & - & 1128 & 148 & 2.115 & 1.5 & 0.6 \\
\hline & B & 423 & 438 & 409 & 564 & 564 & 148 & 2.115 & 1.5 & 0.6 \\
\hline & C & 450 & 425 & 396 & 1093 & - & 161 & 2.115 & 1.5 & 0.6 \\
\hline \multirow{3}{*}{ S15B20 } & $A$ & 423 & 438 & 409 & - & 1128 & 148 & 2.115 & 1.5 & 2 \\
\hline & B & 423 & 438 & 409 & 564 & 564 & 148 & 2.115 & 1.5 & 2 \\
\hline & C & 450 & 425 & 396 & 1093 & - & 161 & 2.115 & 1.5 & 2 \\
\hline
\end{tabular}


Table 2. Test programs. (Self-Elaboration).

\begin{tabular}{|c|c|c|c|c|c|}
\hline Details & Compression tests & Split tensile tests & $\begin{array}{l}\text { Modulus of } \\
\text { Elasticity }\end{array}$ & $\begin{array}{l}\text { Flexure tests } \\
\text { (PCC) }\end{array}$ & Fracture tests \\
\hline Size of specimen & $\begin{array}{r}150 \mathrm{~mm} \times 150 \mathrm{~mm} \\
\times 150 \mathrm{~mm}\end{array}$ & $150 \mathrm{~mm} \times 300 \mathrm{~mm}$ & $150 \mathrm{~mm} \times 300 \mathrm{~mm}$ & $\begin{array}{r}100 \mathrm{~mm} \times 100 \mathrm{~mm} \\
\times 500 \mathrm{~mm}\end{array}$ & $\begin{array}{r}100 \mathrm{~mm} \times 100 \mathrm{~mm} \\
\times 500 \mathrm{~mm}\end{array}$ \\
\hline Procedure as per & IS $516-1959$ & IS 5816 - 1999 & IS $516-1959$ & IS $516-1959$ & RILEM 50-FMC \\
\hline Tested mix ID & All mixtures in Table 3 & All mixtures in Table 3 & All mixtures in Table 3 & All mixtures in Table 3 & $\mathrm{COB}, \mathrm{C} 40 \mathrm{~B}, \mathrm{~S} 15 \mathrm{~B} 6 \mathrm{~B}$ \\
\hline No of specimens & 36 & 36 & 36 & 36 & 9 \\
\hline
\end{tabular}




\section{Specimens and testing methods}

Total of 36 cubes $(150 \mathrm{~mm} \times 150 \mathrm{~mm} \times 150 \mathrm{~mm}), 72$ cylinders $(150 \mathrm{~mm} \times 300 \mathrm{~mm})$ and 45 prisms $(100 \mathrm{~mm} \times 100 \mathrm{~mm} \times$ $500 \mathrm{~mm}$ ) were cast for several test programs given in Table 4. All the specimens were vibrated upon a vibrating table, de-molded after 24 hours of casting and cured for 28 days. To determine the mechanical properties of the HFRC, various test programs have been carried out on hardened concrete conforming standards tabulated in Table 4.

The compressive strength, modulus of elasticity and split tensile strength tests were performed on cube and cylinder specimens in the compressive testing machine with the capacity of $2000 \mathrm{kN}$. The extensometer was fixed and the load was applied continuously as per the loading rate conforming to standards for the stress-strain measurements. A longitudinal compressometer was used to record axial strain which was locked in position using the locking nuts shown in Figure 7 and the dial gauge reading was noted for different load stages until the specimen reaches the ultimate load. he cylinder specimens under split tensile strength were ensured for the same axial plane with the device. As the load reaches maximum approaching failure of the specimen, the load rate reduced simultaneously and the maximum load reached was recorded. The nature of the failure was examined.

The flexural test for the prisms was carried out in a servo-controlled universal testing machine with a capacity of 1100 $\mathrm{kN}$. The specimen was placed in the machine such that the specimen was subjected to two-point loading and the loading rollers were kept at a distance of $13.3 \mathrm{~cm}$ distance apart. The loading rate was adopted as per the codes tabulated above. The load was increased until the specimen failed and the maximum load was recorded. The type of failure on the fractured surfaces was observed.

A fracture test was performed on notched prisms using a servo deflection controlled testing machine. The specimens have a notch depth equal to one-third of the height of the beam. Due to the brittle nature of concrete, the plain concrete prisms were tested at the loading rate of $0.02 \mathrm{~mm} / \mathrm{min}$ and the HFRC was tested at the rate of $0.2 \mathrm{~mm} / \mathrm{min}$ for the deflection limit of $5 \mathrm{~mm}$. The prisms were loaded at the mid-span and the distance between the supports was kept as $400 \mathrm{~mm}$. Load deflection curves were plotted from the results.

Results and discussion

\section{Compressive strength}

The compressive strength of HYFRC with steel and basalt fibers for various mix proportions as per Table 3 are tabulated in Table 5. The test setup of compressive strength is shown in Figure 3. From the results observed from Figure 4 and Table 5, the control concrete with copper slag (C40) showcased enhanced strength than control concrete without copper slag (CO). Of all the three aggregate mix proportions (Mix - A, B, C), B mix was found to perform better than the other two mixtures with and without copper slag i.e, $\mathrm{COB}, \mathrm{C} 40 \mathrm{~B}$. When the steel fibers and basalt fibers are added to the volume fraction of $1.5 \%$ and $0.6 \%$ (S15B6), the strength increment of the mixtures $A, B$ and $C$ were observed with $7.28 \%, 24.74 \%$ and $21.52 \%$ concerning $C 0$ and $5.9 \%, 7.17 \%$ and $6.75 \%$ with respect to $C 40$ as per Table 6 . The strength of the concrete is enhanced with the maintained volume fraction of steel fibers to $1.5 \%$ but the enhanced effect is affected after the basalt fiber content surpasses $0.6 \%$. In the case of adopting the volume fraction of basalt fibers as $2 \%$ along with $1.5 \%$ steel fibers (S15B20), the strength decrement was found to be $33.93 \%, 9.9 \%$ and $24.42 \%$ with respect to $\mathrm{C} 0$ and $35.12 \%, 22.61 \%$ and $33.60 \%$ with respect to $\mathrm{C} 40$ for the mix proportions $\mathrm{A}, \mathrm{B}$ and $\mathrm{C}$.

Effect of basalt fibers: the basalt fiber as mono-fiber at the volume fraction of $2 \%$ did not produce satisfactory results under compression due to the balling effect of fibers and non-homogenous distribution of fibers at the higher volume fraction. When the content of basalt fiber is low in a mixture, the addition of fibers does not necessarily improve the compressive strength, it can even create a negative influence (Wang et al., 2019). The increment in compressive strength is smaller compared to the negative influence of flaws caused by fibers. Being a low modulus fiber compared to steel fibers, the skeleton of the mixture does not support load-bearing property when the volume fraction is low or high other than optimum. From the observed result of optimum volume fraction of steel + basalt fibers, $1.5+0.6 \%$ enhances the compressive strength when the proportion of coarse aggregate is $100 \%$ of $12.5 \mathrm{~mm}$. The basalt fibers dispersed in the pores might improve the features of the Interface transition zone. Since the length and diameter of the steel fiber are larger, the air entrainment of fiber increases the pores in the mixture. The water held into the pores is absorbed by the basalt fibers increasing the bond between the matrix and fibers. Since steel fibers are maintained at a constant volume fraction of $1.5 \%$ the difference in compressive strength was highly influenced by the volume fraction of basalt fibers and aggregate proportions. Early agglomeration of fibers at S15B20 resulted in a dry mixture with less workability. Thus weak interfaces are formed since the maximum volume fraction of basalt fibers absorbs maximum water content. 
Effect of aggregate: since the $\mathrm{C}$ mix had the smaller size of aggregate proportion, the packing of fibers and aggregates took place in a perfect manner (Wang et al., 2019). The water content expelled by the copper slag increases the workability and flow of concrete along with the water content adopted for smaller size aggregate, ensured minimum voids/ pores in the mixture.

As observed from the results, optimum mixing is achieved at the mix S15B6 when steel fiber is $1.5 \%$ and basalt fiber is $0.6 \%$ with $100 \%$ of $12.5 \mathrm{~mm}$ aggregate proportion. Under this combination of fibers, uniform distribution of fibers is achieved in the mixture. Under compression, one type of fiber complements the other type such that, when basalt fibers delay micro crack formation being a low moduli fiber, steel fibers retards the crack propagation creating a bridging effect. Thus the failed specimen were observed only with spalling and not crushed shown in Figure 5 . It was observed that the failure of the specimen due to compression, changes from brittle to ductile due to the integration of fiber combination (Sahoo et al., 2014).
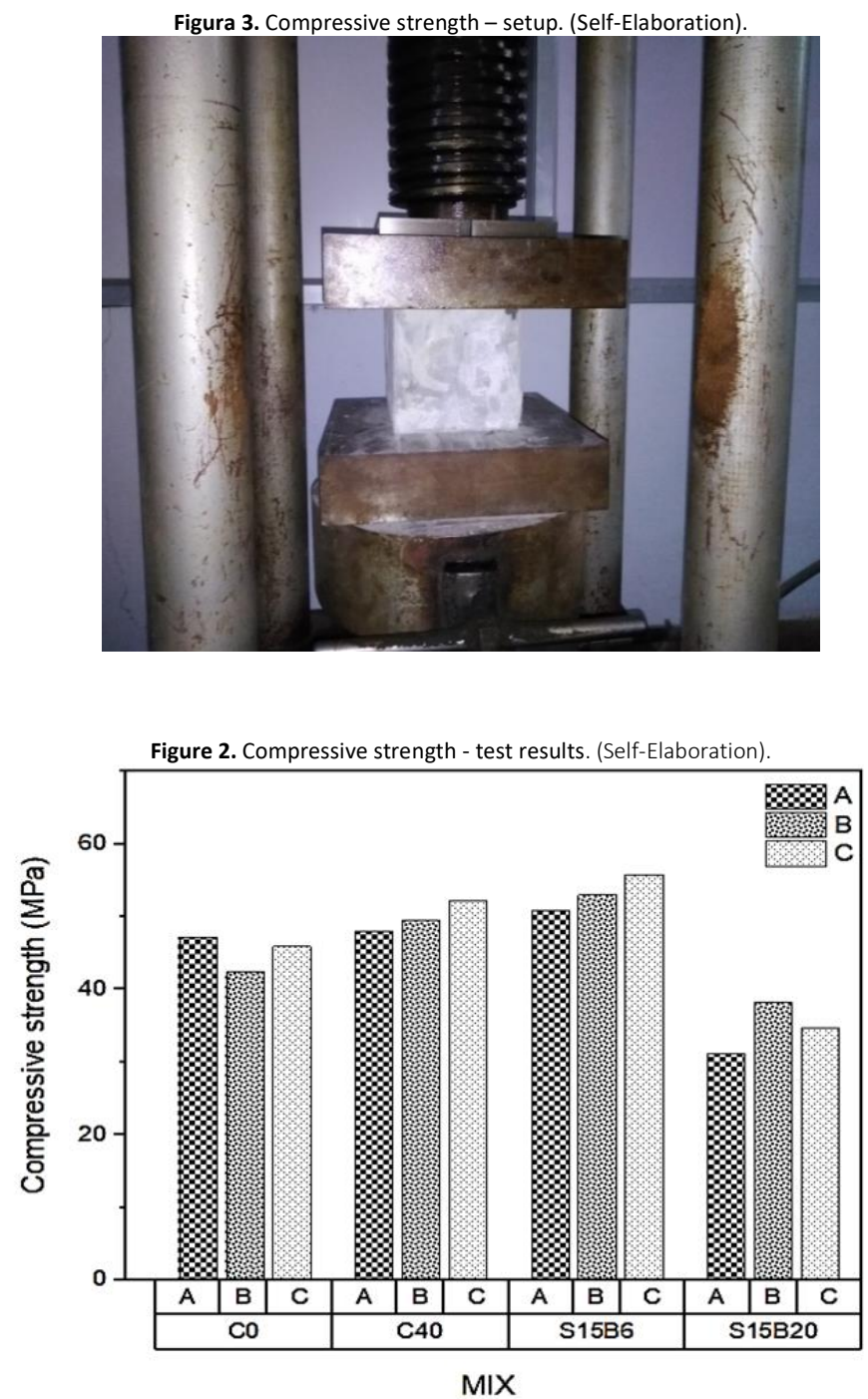
Table 3. Mechanical properties of HyFRC. (Self-Elaboration).

\begin{tabular}{|c|c|c|c|c|c|c|c|c|c|c|c|}
\hline \multirow{2}{*}{\multicolumn{2}{|c|}{ Mixture }} & \multirow{2}{*}{$\begin{array}{l}\text { Basalt } \\
\text { fibers } V_{f} \\
(\%)\end{array}$} & \multirow{2}{*}{$\begin{array}{c}\text { Steel } \\
\text { fibers } V_{f} \\
(\%)\end{array}$} & \multicolumn{2}{|c|}{ Coarse aggregate (\%) } & $\begin{array}{c}\text { Cube } \\
\text { compressive }\end{array}$ & \multirow{2}{*}{$\begin{array}{l}\text { Peak strain } \\
{ }_{c}{ }_{c} \times 10^{-6}\end{array}$} & \multirow[t]{2}{*}{$\begin{array}{l}\text { Split tensile } \\
\text { strength } \mathrm{MPa}\end{array}$} & \multirow[t]{2}{*}{$\begin{array}{l}\text { Flexural Load } \\
\qquad(\mathrm{kN})\end{array}$} & \multirow{2}{*}{$\begin{array}{c}\text { Flexural } \\
\text { Strength } \\
\text { (MPa) }\end{array}$} & \multirow{2}{*}{$\begin{array}{c}\Delta \text { at } \\
\text { maximum } \\
\text { stress }(\mathrm{mm})\end{array}$} \\
\hline & & & & $12.5 \mathrm{~mm}$ & $20 \mathrm{~mm}$ & strength $\mathrm{MPa}$ & & & & & \\
\hline \multirow{3}{*}{$\mathrm{CO}$} & $A$ & 0 & 0 & 0 & 100 & 47.25 & 3050 & 3.07 & 13.25 & 4.54 & 1.77 \\
\hline & B & 0 & 0 & 50 & 50 & 42.53 & 3160 & 3.25 & 14.34 & 5.6 & 2.2 \\
\hline & $\mathrm{C}$ & 0 & 0 & 100 & 0 & 45.98 & 4520 & 3.53 & 15.8 & 8.53 & 1.97 \\
\hline \multirow{3}{*}{ C40 } & A & 0 & 0 & 0 & 100 & 48.12 & 3414 & 3.52 & 14.75 & 9.68 & 2.07 \\
\hline & B & 0 & 0 & 50 & 50 & 49.5 & 4613 & 4.25 & 27.07 & 10.56 & 1.76 \\
\hline & $\mathrm{C}$ & 0 & 0 & 100 & 0 & 52.34 & 4587 & 4.67 & 32.87 & 13.15 & 2.78 \\
\hline \multirow{3}{*}{ S15B6 } & A & 1.5 & 0.6 & 0 & 100 & 50.96 & 6013 & 5.66 & 33.79 & 15.98 & 3.91 \\
\hline & B & 1.5 & 0.6 & 50 & 50 & 53.05 & 5427 & 7.41 & 37.4 & 19.6 & 3.43 \\
\hline & $\mathrm{C}$ & 1.5 & 0.6 & 100 & 0 & 55.875 & 5120 & 7.36 & 25.6 & 11.52 & 5.46 \\
\hline \multirow{3}{*}{ S15B20 } & A & 1.5 & 2 & 0 & 100 & 31.22 & 2613 & 4.95 & 15.89 & 7.29 & 3.95 \\
\hline & B & 1.5 & 2 & 50 & 50 & 38.31 & 4026 & 5.62 & 11.22 & 5.2 & 2.92 \\
\hline & $\mathrm{C}$ & 1.5 & 2 & 100 & 0 & 34.75 & 2427 & 4.08 & 7.23 & 3.68 & 2.45 \\
\hline
\end{tabular}

Figure 3. Failed specimen under compression - S15B6B. (Self-Elaboration).

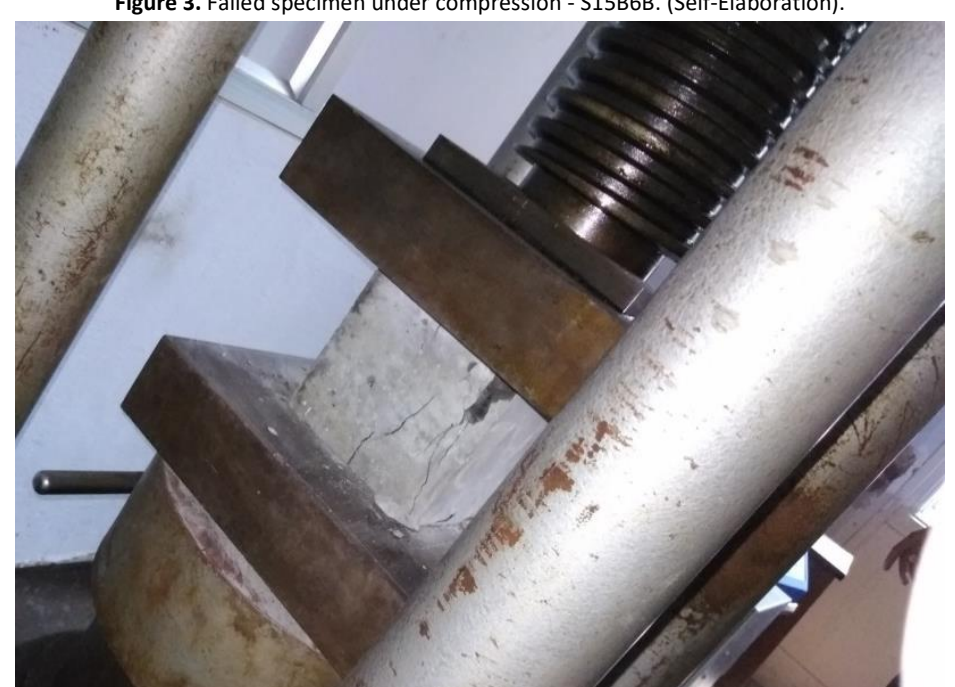


Table 4. Strength effectiveness of mixtures under compression. (Self-Elaboration).

\begin{tabular}{|c|c|c|c|c|c|c|c|c|}
\hline \multirow{2}{*}{\multicolumn{2}{|c|}{ Mixture }} & \multirow{2}{*}{$\begin{array}{l}\text { Cube compressive } \\
\text { strength } \mathrm{MPa}\end{array}$} & \multicolumn{6}{|c|}{ Strength effectiveness w.r.t } \\
\hline & & & COA & $\mathrm{COB}$ & $\mathrm{COC}$ & C40A & C40B & $\mathrm{C} 40 \mathrm{C}$ \\
\hline \multirow{3}{*}{$\mathrm{CO}$} & $A$ & 47.25 & - & & & -1.81 & & \\
\hline & B & 42.53 & & - & & & 14.10 & \\
\hline & C & 45.98 & & & - & & & 12.15 \\
\hline \multirow{3}{*}{$\mathrm{C} 40$} & $A$ & 48.12 & 1.84 & & & - & & \\
\hline & B & 49.5 & & 16.39 & & & - & \\
\hline & $C$ & 52.34 & & & 13.83 & & & - \\
\hline \multirow{3}{*}{ S15B6 } & $A$ & 50.96 & 7.28 & & & 5.90 & & \\
\hline & B & 53.05 & & 24.74 & & & 7.17 & \\
\hline & C & 55.875 & & & 21.52 & & & 6.75 \\
\hline \multirow{3}{*}{ S15B20 } & $A$ & 31.22 & -33.93 & & & -35.12 & & \\
\hline & B & 38.31 & & -9.9 & & & -22.61 & \\
\hline & $C$ & 34.75 & & & -24.42 & & & -33.60 \\
\hline
\end{tabular}

The peak strain and the plotted stress-strain curves for all the mix ID showed in Figure 6 and 9. The stress-strain set up shown in Figure 7. From the recorded stress-strain data for the hybrid combination of non-metallic - metallic fibers (steel + basalt), the following observations are made. Figure 9 (a) and 9 (b) exhibit the stress-strain behavior of control concrete without fibers. It is observed that $100 \%$ of $20 \mathrm{~mm}$ aggregate without copper slag COA projected the highest strain in fig $8(\mathrm{a})$. Whereas in Figure $8(\mathrm{~b})$. specimen with copper slag and two different proportion of aggregate (B - 50\% of $12.5 \mathrm{~mm}+50 \%$ of $20 \mathrm{~mm}$ and $\mathrm{C}-100 \%$ of $12.5 \mathrm{~mm}$ ) C40B, C40C showed the highest strain behavior but less than COA.

To enhance the stress-strain behavior non-metallic (basalt) + metallic (steel) fibers were integrated at the volume fraction of $0.6 \%+1.5 \%$. Thus in fig $9(\mathrm{C})$, it is evident that $\mathrm{S} 15 \mathrm{~B} 6 \mathrm{~B}$ and $\mathrm{C}$ contributed more or less the same peak stress. Compared to the control concrete, the peak stress slightly increases with the integration of steel and basalt fibers. Of the same category, the S15B6A mix recorded the highest peak strain observed from figure 6. At this point, figure 9 (d) steel fibers are constantly maintained at the volume fraction of $1.5 \%$ when the volume fraction of basalt fibers at $2 \%$. The peak stress reduced drastically indicating the excess quantity of basalt fibers hinders the strain capacity of concrete. S15B20 showcased the highest peak stress compared to the other mixes. Thus basalt fibers can enhance strain capacity not more than $0.6 \%$ of volume fraction. When the steel fibers are constant ( $v f-1.5 \%$ ) and basalt fibers at $0.6 \%$, the hybridization is highly effective (Sun et al., 2018).

Generally under hybridization non-metallic behavior enhances the pre-peak behavior by retarding the micro crack at the reduced stress levels. Whereas metallic fibers enhance the post-peak behavior by retarding macro cracks at reduced stress levels. Thus the hybridization is effective in arresting multi-scale cracks at different stress levels. The increase in strain at peak stress was observed under the ID S15B6A (Koniki \& Prasad, 2019). Of all the mixes under C0, C40 and S15B6 and S15 B20 - B mix showcased linear behavior in the initial portion of the curve up to 85 to $90 \%$ of peak strength then it was observed with a non-linear variation. The failed specimens under compressive stress-strain are shown in figure 8 . 


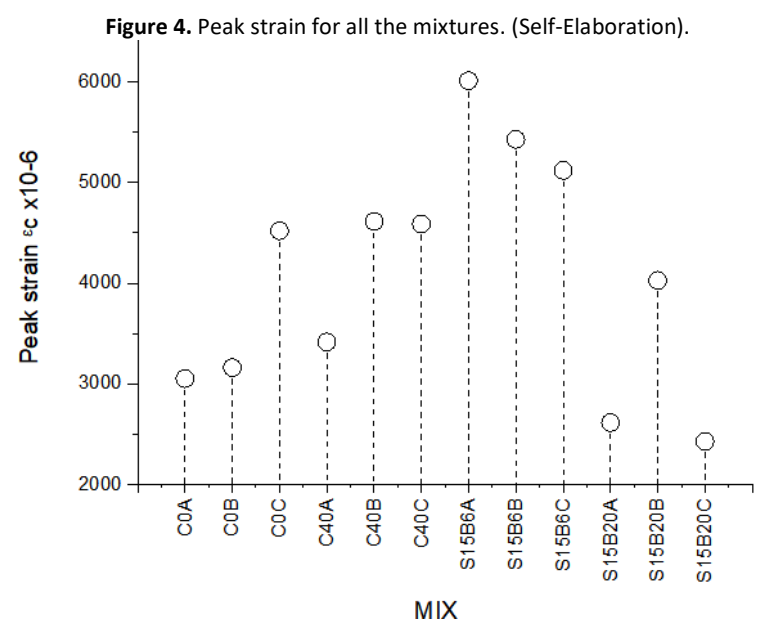

Figure 5. Stress-strain test set up. (Self-Elaboration).
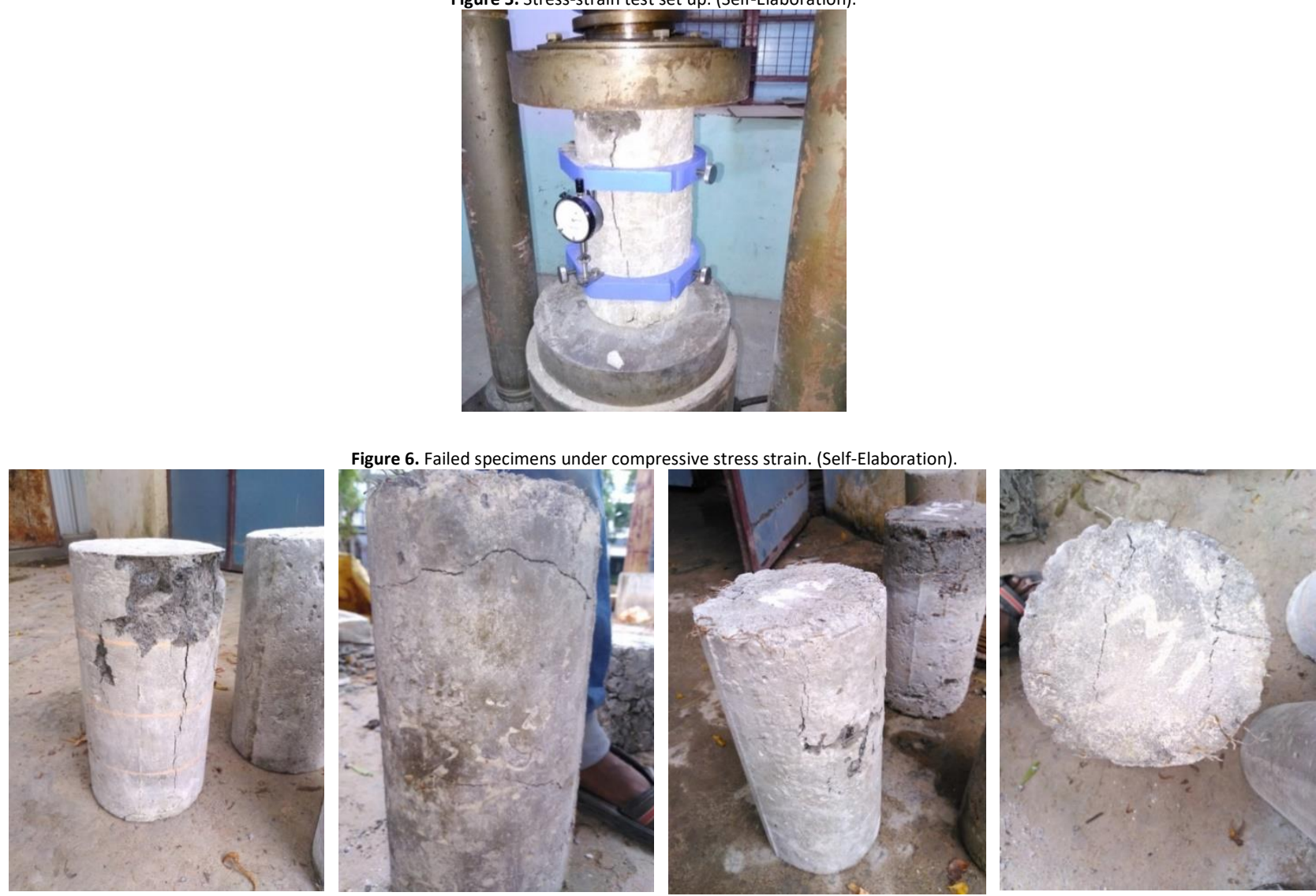


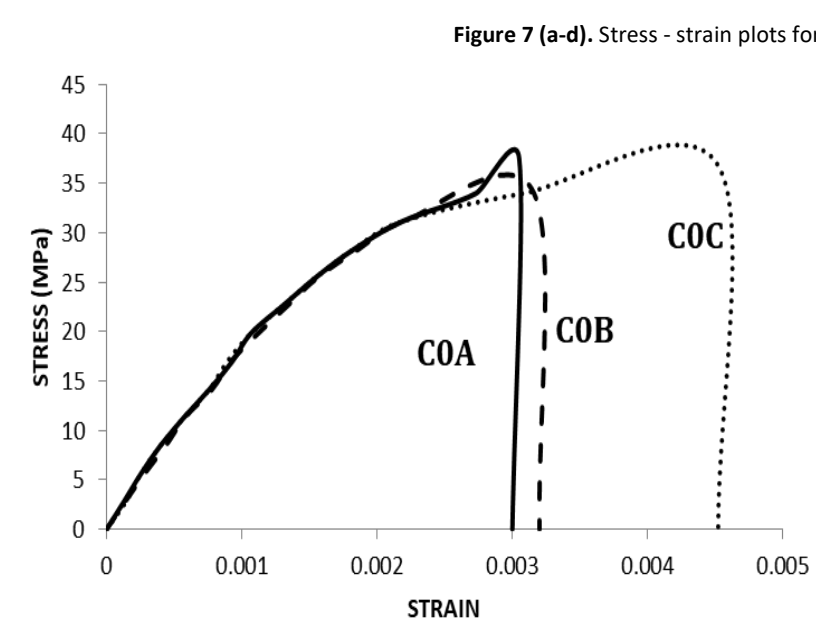

a)
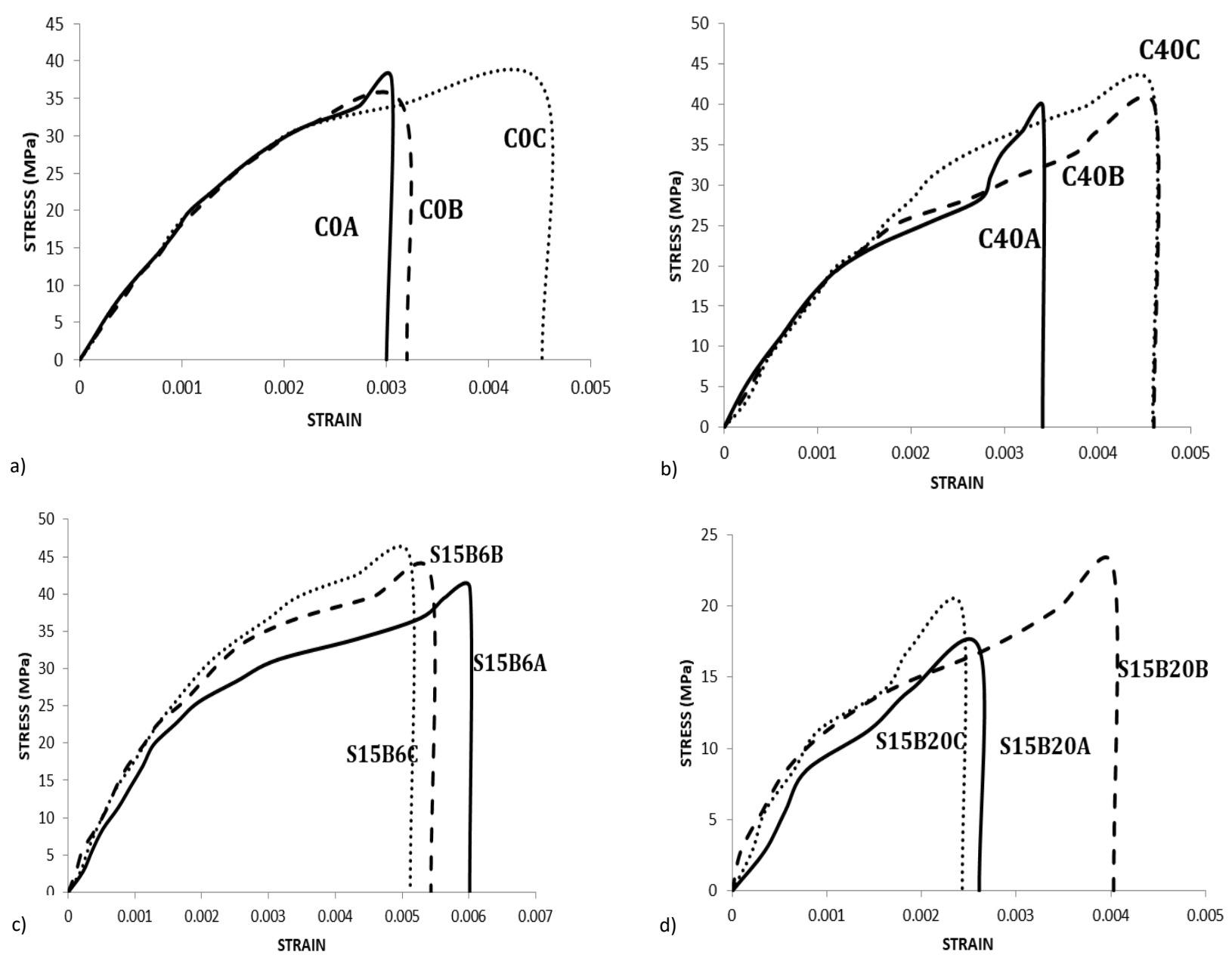

\section{Split tension strength}

Uniaxial compression loading was applied on the cylinder specimens gradually and the split tensile strength was computed. The experimental setup is shown in Figure 10. Summarized values are tabulated for both plain cement concrete and hybrid fiber reinforce concrete in table 5. The addition of fibers had a positive influence on the split tensile strength compared to the plain concrete (Sahoo et al., 2014). The highest tensile strength was recorded by S15B6B which has been increased by $74 \%$ with respect to $C 40 B$ tabulated in table 7 . The test results of the plain cement concrete have been observed and the results with $\mathrm{C}$ mix under $\mathrm{C} 0$ and $\mathrm{C} 40$ exhibited enhanced results. This may be due to the retained water content sufficient for the bonding property at the aggregate proportion of $100 \%$ of $12.5 \mathrm{~mm}$. At the mix S15B6 - when steel fibers + basalt fibers at the volume fraction $1.5+0.6 \%$, under the mixture B with $50 \%$ of $20 \mathrm{~mm}$ aggregate and $50 \%$ of $12.5 \mathrm{~mm}$ aggregate showcased predominant result due to the packaging of fine and coarse aggregate along with heterogeneous fiber distribution (Wang et al., 2019).

The macro and microfibers distribute unevenly due to which the macro voids must be filled by the coarse aggregate of various sizes and it was found to be effective. The microvoids were compensated by the fine aggregates (River sand + copper slag). Maintaining the constant volume fraction of steel fibers (1.5\%) due to the difficulties in workability as macro fibers, the increase in volume fraction of basalt fibers as $2 \%$ reduces the strength property of concrete compared to the mixture S15B6. The mix S15B20-B exhibited a 32\% strength increment with respect to C40B as per table 7. The increased volume fraction of basalt fibers generated porosity which was not able to compensate by the water retention from copper slag. The higher volume fraction weakened the interface of concrete resulting in reduced strength (Wang et al., 2019). The presence of copper slag had the advantageous effect of water retention which provided minimum complementation to the mixture with more basalt fibers. Even though the volume fraction of basalt fibers reduced to the performance of all three mixes under S15B20, it behaved better than the control concrete.

It is evident from the failure pattern of cylindrical specimens that under PCC, it did split into halves. Whereas HFRC specimens maintained the integrity such that they did not collapse completely shown in Figure 12 except the fiber 
bridging action was enabled by redistributing the stresses along cracked surfaces (Sahoo et al., 2014). The effect of reinforcement disappears when the tensile stress overtakes the bond strength (Wang et al., 2019).

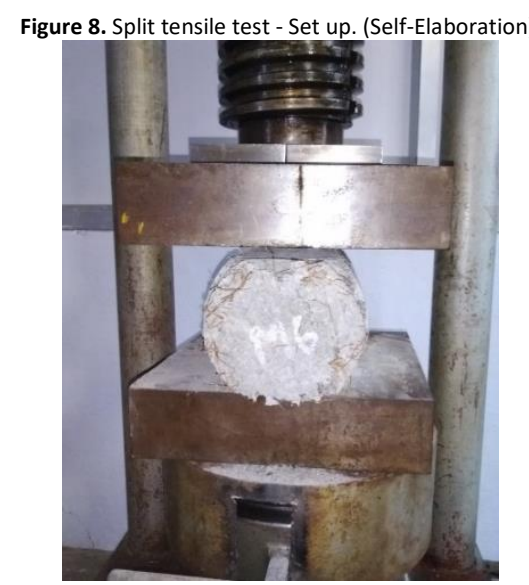

Figure 9. Test results of split tensile strength and flexural strength under various mixtures. (Self-Elaboration).

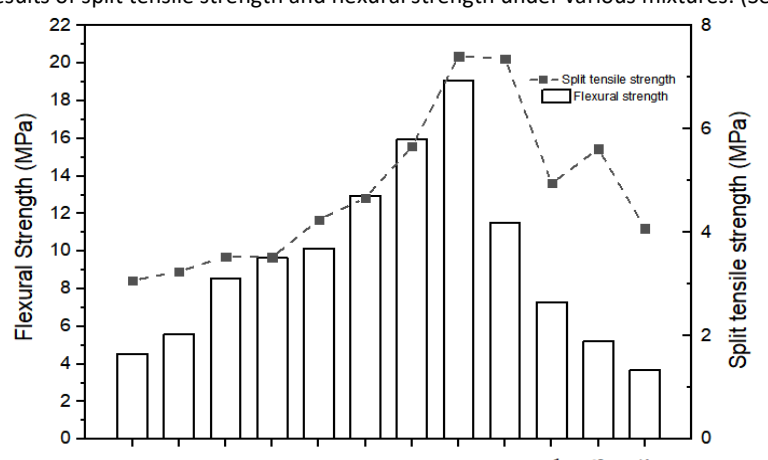

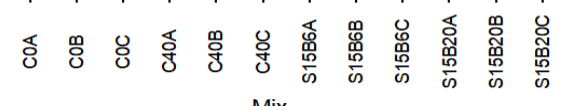

Mix

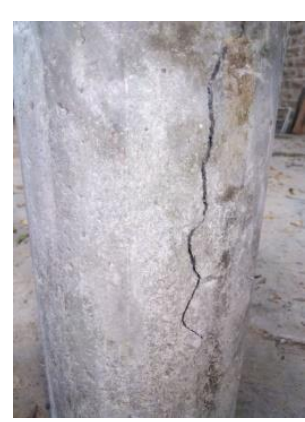

Figure 10. Failed specimens under split tension. (Self-Elaboration).
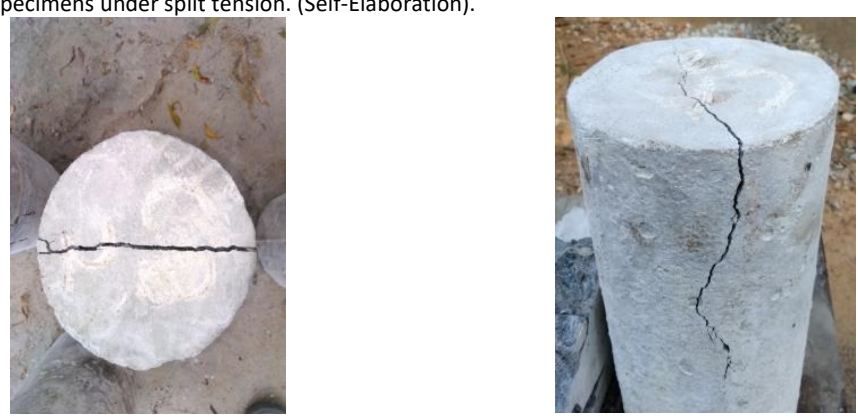

Table 5. Strength effectiveness of mixtures under split tension. (Self-Elaboration).

\begin{tabular}{|c|c|c|c|c|c|c|c|c|}
\hline \multicolumn{2}{|c|}{ Mixture } & $\begin{array}{l}\text { Split tensile } \\
\text { strength } \mathrm{MPa}\end{array}$ & \multicolumn{6}{|c|}{ Strength effectiveness w.r.t } \\
\hline \multirow{2}{*}{$\mathrm{CO}$} & $A$ & 3.07 & - & & & -12.78 & & \\
\hline & $\mathrm{C}$ & 3.53 & & & - & & & -24.41 \\
\hline C40 & $A$ & 3.52 & 14.66 & & & - & & \\
\hline \multirow{3}{*}{ S15B6 } & $A$ & 5.66 & 84.36 & & & 60.79 & & \\
\hline & $\mathrm{B}$ & 7.41 & & 128 & & & 74.35 & \\
\hline & $\mathrm{C}$ & 7.36 & & & 108.5 & & & 57.60 \\
\hline \multirow{2}{*}{ S15B20 } & $A$ & 4.95 & 61.24 & & & 40.63 & & \\
\hline & $\mathrm{B}$ & 5.62 & & 72.92 & & & 32.24 & \\
\hline
\end{tabular}




\section{Flexural strength}

Graphs are shown in Figure 13 and 14 summarize the flexural strength properties of the mixes C0, C40, S15B6 and S15B20 for the coarse aggregate proportions $-A, B$ and C. The test setup is shown in Figure 15. The maximum strength under flexure was observed under the hybrid combination S15B6-B up to $85.6 \%$ with respect to C40B and $250 \%$ with respect to $\mathrm{COB}$ shown in Table 8 . The optimum fiber content of the hybrid combination under flexure showcased similar behavior as tensile behavior. Detailed test results are tabulated in Table 5.

Characteristics of load deflection curve : the load-deflection curves of the HFRC are shown in Figure 14. A schematic pattern of the curve has three definite stages as Elastic, deflection - hardening and deflection softening as follows.

Stage I: Initiation of microcracking, where the load gradually increases proportionate to the displacement up to the initial crack formation. Then a minor reduction in the load increment is observed.

Stage II: After a minor reduction, the load rises slowly up to the peak stress which exhibits a deflection hardening behavior.

Stage III: Initiation of micro-cracks propagates into continuous macro cracks, resulting in a reduction in load with increased deflection. As the macro cracks grow towards the top of the prism it loses its ability to carry the load (Li et al., 2018).

The following observations are made with the effect of fibers, copper slag and coarse aggregate proportions: Figure 13 exhibits the load-deflection curve of Plain cement control concrete with and without copper slag. Of all the control mixes, concrete with copper slag with $100 \%$ of $12.5 \mathrm{~mm}$ (C40-C) coarse aggregate showcased higher strength, Due to the water retention ability, the pores $w$ ere minimized with the effective use of copper slag resulted in the highest flexural tensile strength. The curve pattern of $\mathrm{COA}, \mathrm{COB}$ and $\mathrm{COC}$ exhibited brittle behavior. The load suddenly drops after reaching the peak point. The ascending branch for all three mixes is similar till the first crack point. The curve of C40A, C4OB and C40C showed a mild ductile behavior. In the ascending branch, after the first crack load, deviations in the curve up to the deflection hardening point were observed. The descending part exhibits mild softening behavior mainly at $\mathrm{C} 4 \mathrm{~B}$ avoiding sudden load drop to some extent. The flexure behavior and the load-deflection pattern were found to be superior for HFRC compared to PCC (Teng et al., 2018).

The initiation of crack formation to propagation was observed under all HYFRC, a sample mix was shown in Figure 16. Of the group of S15B6 mixtures, the ascending portion is highly influenced by the micro basalt fibers exhibiting delay in cracking observed till peak load. The sudden load drop after the hardening behavior, the hooked end steel fibers take up the role of bridging action shown in figure 17 gives a softening behavior at the descending branch (Guler, 2018; Li et al., 2018). Maximum flexural strength was recorded by S15B6-B with minimum deflection. When the volume fraction of micro basalt fibers is increased to $2 \%$ with constant $\mathrm{Vf}$ of steel fibers $1.5 \%$, linear behavior was observed for all the mixtures S15B20A, S15B20B and S15B20C till the first crack load. The increased volume fraction of microfibers redistributed the stresses in a likely manner till peak stress and the smoothening part were very good for all the mix ID. Even though the mix with $2 \%$ basalt fibers and $1.5 \%$ steel fibers did not perform better when compared to C40, S15B2OB and S15B20C were considerable under deflection softening behavior.

The effect of coarse aggregate in the $\mathrm{B}$ and $\mathrm{C}$ mix played a dominant role under flexure in which the smaller aggregate size provides more ductility compared to the larger aggregate. Since B mix was packed with both the aggregate sizes $12.5 \mathrm{~mm}$ and $20 \mathrm{~mm}$ and $\mathrm{C}$ mix was with only $12.5 \mathrm{~mm}$ along with copper slag, the homogenous mix was ensured promoting ductile behavior. From the failure pattern of the specimens in Figure 16 and 17, it is evident that the incorporation of hybrid fibers promotes the post-peak strength of the concrete. The mix $\mathrm{CO}$ and $\mathrm{C} 40$ failed from the sudden load drop. The mixes S15B6 and S15B20 did not collapse even after the propagation of cracks till the top of the prism. The microfibers retarded the crack initiation and the enlarged macro cracks were controlled by the bridging action of the hooked end fiber anchorage. The micro basalt fibers were not visible much at the fractured section of the prism. And the steel fibers failed either by pullout or de-bonding seen in Figure 18. 
Figure 11. Load - Deflection curves for PCC. (Self-Elaboration).
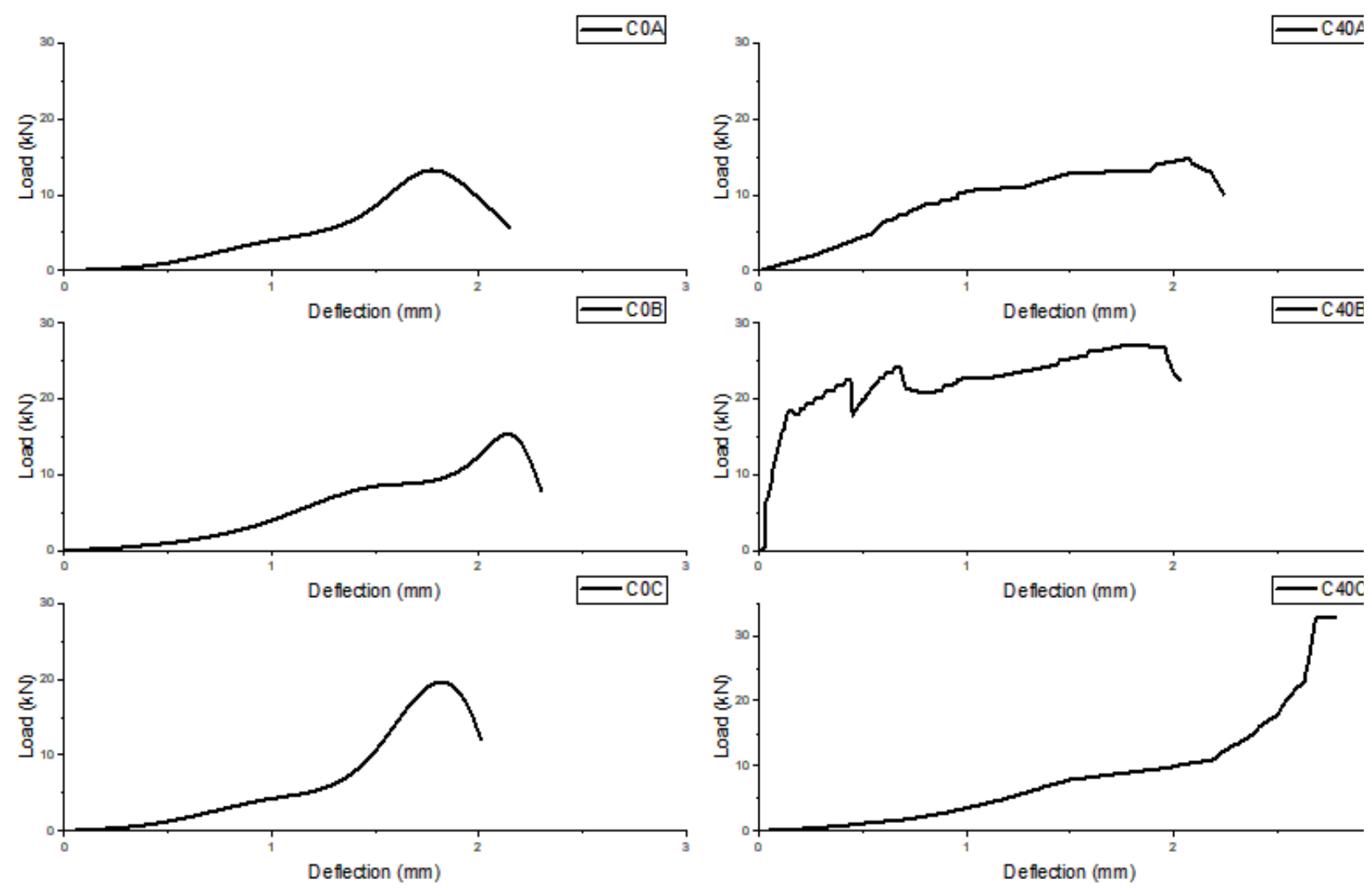

Table 6. Strength effectiveness for the mixtures under flexure. (Self-Elaboration).

\begin{tabular}{|c|c|c|c|c|c|c|c|c|}
\hline \multicolumn{2}{|c|}{ Mixture } & \multirow{2}{*}{$\begin{array}{c}\text { Flexural } \\
\text { strength } \\
(\mathrm{MPa})\end{array}$} & \multicolumn{6}{|c|}{ Strength effectiveness w.r.t } \\
\hline & & & COA & $\mathrm{COB}$ & $\mathrm{COC}$ & C40A & $\mathrm{C} 40 \mathrm{~B}$ & C40C \\
\hline & $A$ & 4.54 & - & & & -53.01 & & \\
\hline \multirow[t]{3}{*}{$\mathrm{CO}$} & $\mathrm{B}$ & 5.6 & & - & & & -46.97 & \\
\hline & $\mathrm{C}$ & 8.53 & & & - & & & -35.13 \\
\hline & $A$ & 9.68 & 113.22 & & & - & & \\
\hline \multirow[t]{3}{*}{$\mathrm{C} 40$} & $\mathrm{~B}$ & 10.56 & & 88.57 & & & - & \\
\hline & $\mathrm{C}$ & 13.15 & & & 54.16 & & & - \\
\hline & $A$ & 15.98 & 251.98 & & & 65.08 & & \\
\hline \multirow[t]{3}{*}{ S15B6 } & $\mathrm{B}$ & 19.6 & & 250.00 & & & 85.61 & \\
\hline & $\mathrm{C}$ & 11.52 & & & 35.05 & & & -12.40 \\
\hline & $A$ & 7.29 & 60.57 & & & -24.69 & & \\
\hline \multirow[t]{2}{*}{ S15B20 } & $\mathrm{B}$ & 5.2 & & -7.14 & & & -50.76 & \\
\hline & $\mathrm{C}$ & 3.68 & & & -56.86 & & & -72.02 \\
\hline
\end{tabular}


Figure 12. Load- Deflection curves for HYFRC. (Self-Elaboration).
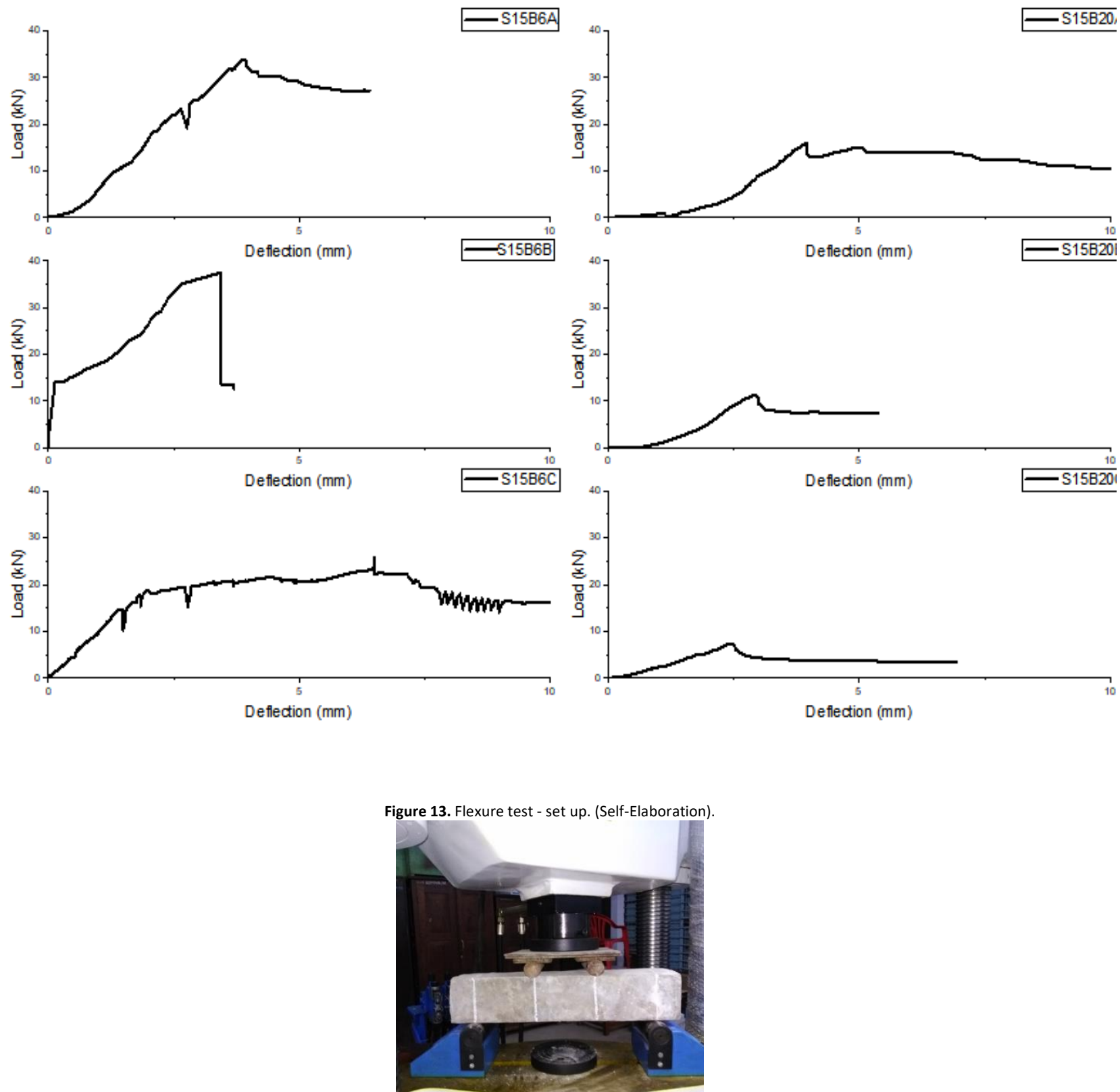

Figure 14. a) Initiation of crack; b) Propagation of crack. (Self-Elaboration).
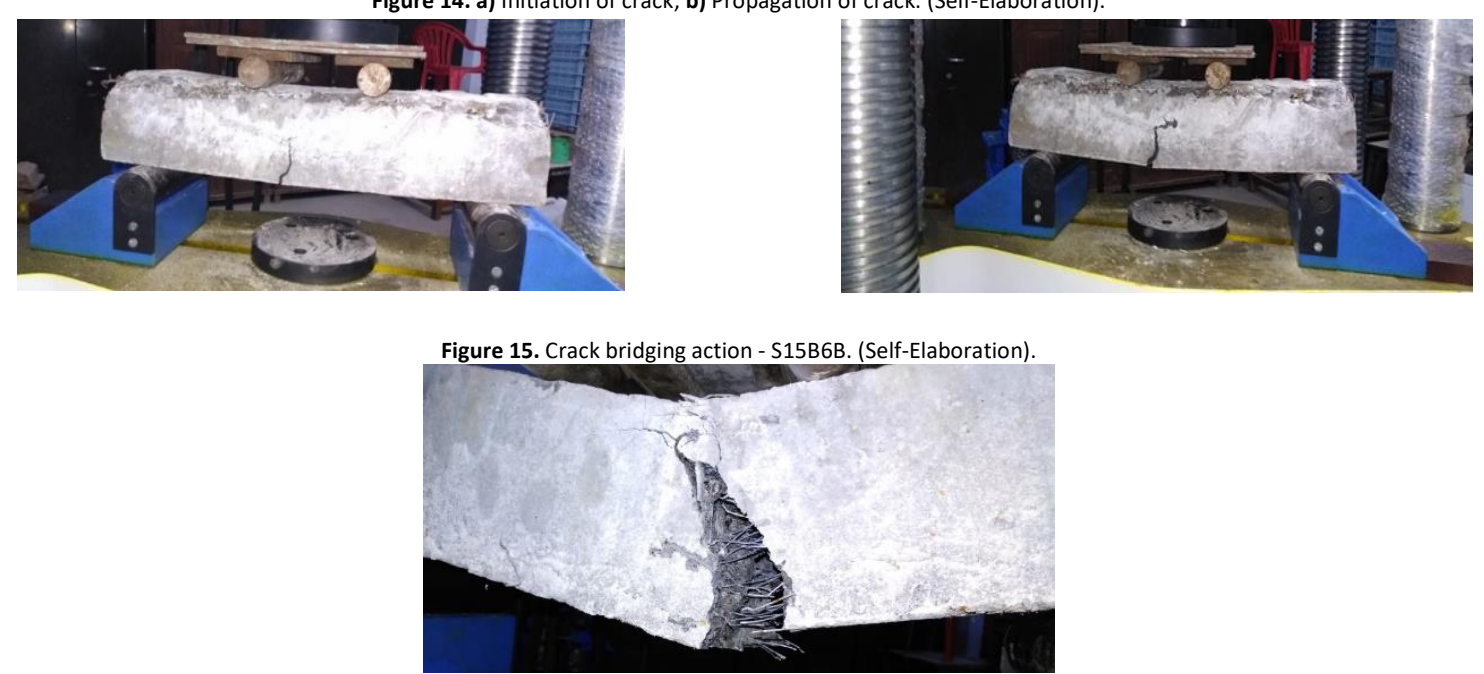


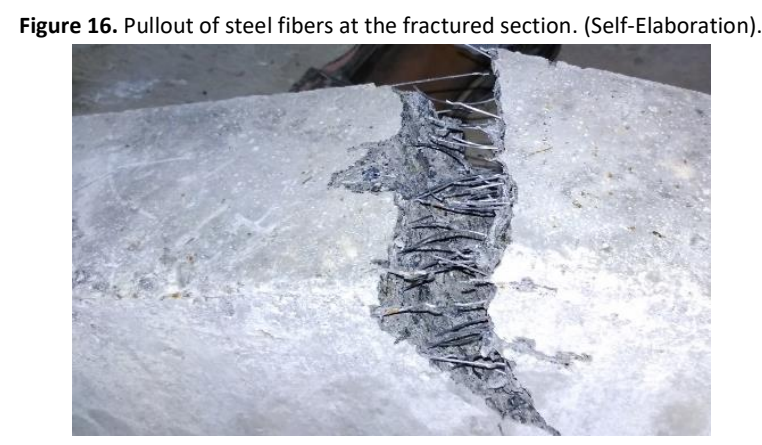

\section{Flexural toughness}

The flexural toughness of the HFRC was evaluated based on the standards JSCE SF4 and ASTM 1609. The toughness parameter was calculated using JSCE at the deflection point L/150 (Guler, 2018). The parameters were determined at two deflection points L/600 and L/150 using ASTM standards. The values evaluated from both the standards are found to be pre-peak toughness (Guler, 2018). Table 9 presents various toughness parameters such as T150, TF150 under JSCE and P600, T600, $6600, \mathrm{P} 150, \mathrm{~T} 150$ and $\sigma 150$ under ASTM. Where,

P150 - Load under the deflection point L/150,

T150 - Toughness under the deflection point L/150,

$\sigma 150$ - Flexural strength under the deflection point $L / 150$,

TF150 - Toughness factor under the deflection point L/150,

P600 - Load under the deflection point L/600,

T600 - Toughness under the deflection point $L / 600$,

$\sigma 600$ - Flexural strength under the deflection point $L / 600$

Under JSCE evaluation, the highest toughness was recorded as $80.52 \mathrm{kN} . \mathrm{mm}$ by the mix S15B6-B shown in Figure 19. At the same deflection, other mixes $A$ and $C$ showed $43.35 \mathrm{kN} . \mathrm{mm}$ and $44.66 \mathrm{kN}$. mm. As the volume fraction of basalt fibers increases at the mixture S15B20 the toughness was reduced between $9.88-11.94$ kN.mm. 


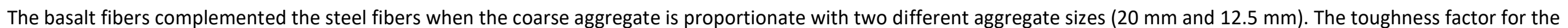

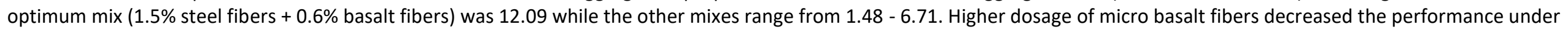

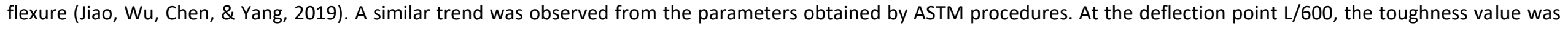

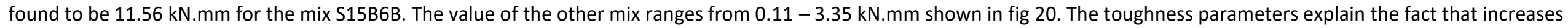

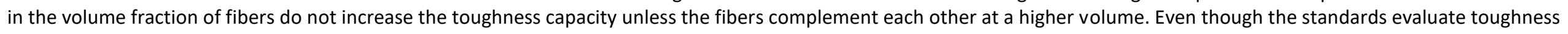

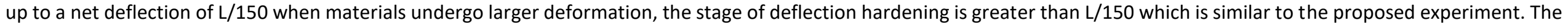

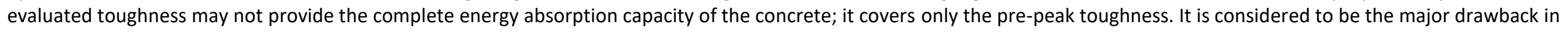
using the above standards in the evaluation of toughness for materials with larger deformations (Kim, D., Naaman, A., Eltawil, 2008).

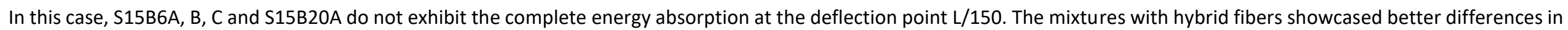

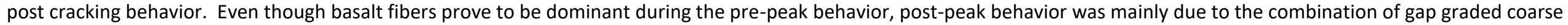
aggregate in complement to the hooked end steel fibers (L. Zhang, Liu, Liu, Zhang, \& Han, 2018).

Table 7. Toughness parameters of HYFRC. (Self-Elaboration).

\begin{tabular}{|c|c|c|c|c|c|c|c|c|c|c|c|}
\hline \multirow[b]{2}{*}{ ID } & \multicolumn{4}{|c|}{ Parameters based on JSCE SF4 } & \multicolumn{7}{|c|}{ Parameters based on ASTM C1609 } \\
\hline & $\begin{array}{c}\mathrm{T}_{150} \\
\text { (kN.mm) }\end{array}$ & $\begin{array}{l}\Delta_{150} \\
(\mathrm{~mm})\end{array}$ & $\begin{array}{l}\mathrm{TF}_{150} \\
(\mathrm{MPa})\end{array}$ & $\begin{array}{l}P_{600} \\
(k N)\end{array}$ & $\begin{array}{c}\sigma_{600} \\
\left(\mathrm{~N} / \mathrm{mm}^{2}\right)\end{array}$ & $\begin{array}{c}\Delta_{600} \\
(\mathrm{~mm})\end{array}$ & $\begin{array}{l}P_{150} \\
(k N)\end{array}$ & $\begin{array}{c}\sigma_{150} \\
\left(\mathrm{~N} / \mathrm{mm}^{2}\right)\end{array}$ & $\begin{array}{c}\Delta_{150} \\
\left(\mathrm{~N} / \mathrm{mm}^{2}\right)\end{array}$ & $\begin{array}{c}T_{600} \\
\text { (kN.mm) }\end{array}$ & $\begin{array}{c}\mathrm{T}_{150} \\
\text { (kN.mm) }\end{array}$ \\
\hline S15B6A & 43.35 & \multirow{6}{*}{3.33} & 6.51 & 3.92 & 1.96 & \multirow{6}{*}{0.83} & 28.77 & 14.385 & \multirow{6}{*}{3.33} & 1.17 & 43.35 \\
\hline S15B6B & 80.52 & & 12.09 & 16.9 & 8.45 & & 36.01 & 18.01 & & 11.56 & 80.52 \\
\hline S15B6C & 44.66 & & 6.71 & 8.22 & 4.11 & & 19.98 & 9.99 & & 3.35 & 44.66 \\
\hline S15B20A & 9.88 & & 1.48 & 0.59 & 0.295 & & 10.86 & 5.43 & & 0.23 & 9.88 \\
\hline S15B20B & 14.51 & & 2.18 & 0.52 & 0.26 & & 7.86 & 3.93 & & 0.11 & 14.51 \\
\hline S15B20C & 11.94 & & 1.79 & 1.88 & 0.94 & & 3.98 & 1.99 & & 0.61 & 11.94 \\
\hline
\end{tabular}




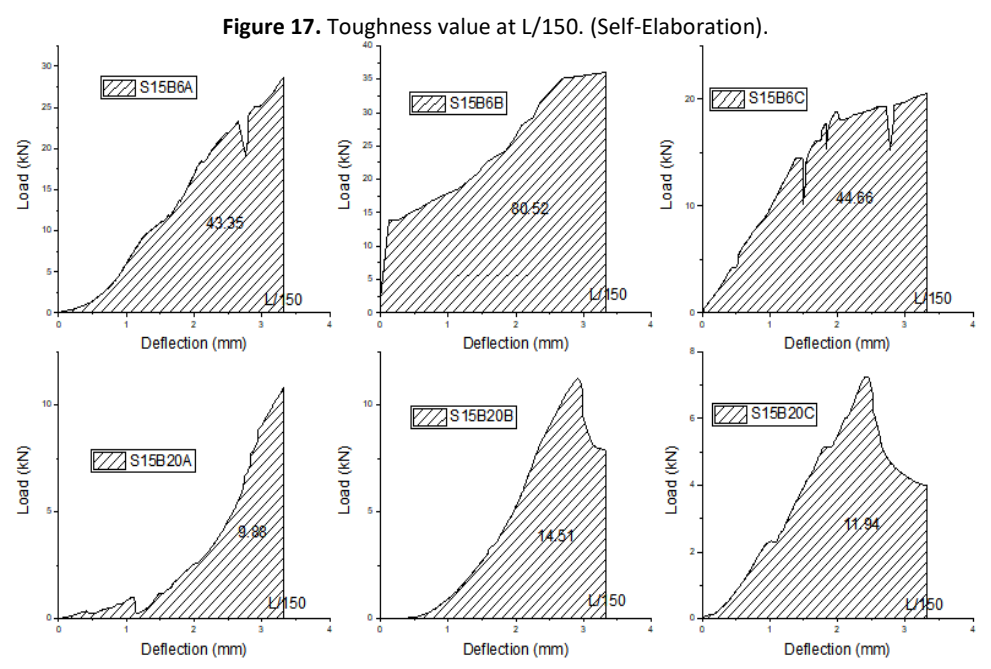

Figure 18. Toughness value at $\mathrm{L} / 600$. (Self-Elaboration).
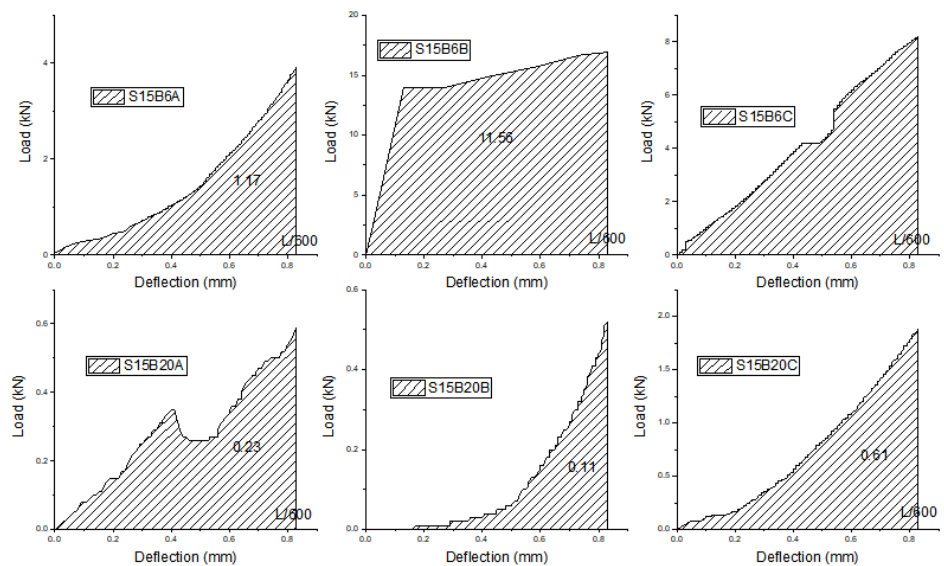

\section{Synergy effect of hybrid fibers}

Hybrid fibers in the concrete need to develop a positive hybrid effect to enhance the mechanical properties efficiently compared to its individual fiber. The effect of synergy on Compression, Tension and Flexure shall be analyzed based on the following coefficients given by Dehong wang et al (Wang et al., 2019).

$$
\begin{gathered}
\propto_{x 1}=\frac{\left(\frac{f_{c}}{f_{c 0}}\right)_{H F}+\left(\frac{f_{c}}{f_{c 0}}\right)_{\min I F}}{\left(\frac{f_{c}}{f_{c 0}}\right)_{\text {maxIF }}+\left(\frac{f_{c}}{f_{c 0}}\right)_{\operatorname{minIF}}} \\
\propto_{x 2}=\frac{\left(\frac{f_{c}}{f_{c 0}}\right)_{H F}+\left(\frac{f_{c}}{f_{c 0}}\right)_{\max I F}}{\left(\frac{f c}{f_{c 0}}\right)_{\text {maxIF }}+\left(\frac{f_{c}}{f_{c 0}}\right)_{\min I F}}
\end{gathered}
$$

Where, $\propto_{x 1}$ and $\propto_{x 2}$ are synergy co-efficients, $x$ denotes the nature of strength i.e. $\propto_{c 1}$ and $\propto_{c 2}$ represents the synergy co-efficients of compressive strength, $\propto_{t 1}$ and $\propto_{t 2}$ represents co-efficients of split tensile strength and $\propto_{f 1}$ and $\propto_{f 2}$ represents co-efficients of flexural strength. In the equation $\mathrm{fc}$ denotes the strength of concrete with fibers and fc0 denotes the strength of concrete without fibers, HF denotes Hybrid fibers, minlF denotes minimum enhancement coefficient of individual fiber (steel of basalt fiber), maxIF represents maximum enhancement co-efficient of individual fiber (steel or basalt fiber). From the calculated co-efficients given in table 10, When $\propto_{x 1}$ is greater than 1 then both the fibers in the concrete have a positive hybrid effect. When $\alpha_{x 1}$ is lesser than 1, the synergy effect depends of $\propto_{x 2}$. If $\propto_{x 2}$ is greater than 1 , then the mixture has a positive hybrid effect. If it is less than 1 , it has a negative synergy effect. The co-efficients are plotted as a graph shown in Figure 21. 
Table 8. Synergy strength co-efficients. (Self-Elaboration).

\begin{tabular}{ccccccc}
\hline Mix ID & $\alpha_{\mathrm{c} 1}$ & $\alpha_{\mathrm{c} 2}$ & $\alpha_{\mathrm{t} 1}$ & $\alpha_{\mathrm{t} 2}$ & $\alpha_{\mathrm{f} 1}$ & $\alpha_{\mathrm{f} 2}$ \\
\hline S15B6A & 0.945 & 1.018 & 0.907 & 1.202 & 0.981 & 1.324 \\
S15B6B & 0.965 & 1.037 & 1.074 & 1.368 & 0.985 & 1.329 \\
S15B6C & 0.992 & 1.064 & 1.069 & 1.363 & 0.798 & 1.142 \\
S15B20A & 0.668 & 1.143 & 0.864 & 0.926 & 0.670 & 0.855 \\
S15B20B & 0.760 & 1.235 & 0.918 & 0.979 & 0.595 & 0.780 \\
S15B20C & 0.714 & 1.189 & 0.795 & 0.856 & 0.540 & 0.725 \\
\hline
\end{tabular}

It is observed from the table that S15B6B exhibits a higher positive synergy effect from the three synergy strength coefficients. S15B6C and S15B6A showcased a positive hybrid effect next to S15B6B. The mixture S15B20 showed moderate results at $B$ mix and poor hybrid effect at the other mixes $A$ and $C$. Based on the synergy effect, the volume fraction is suggested as $1.5 \%$ of steel fibers and $0.6 \%$ of basalt fibers with $50-50$ proportions of $20 \mathrm{~mm}-12.5 \mathrm{~mm}$ coarse aggregate.

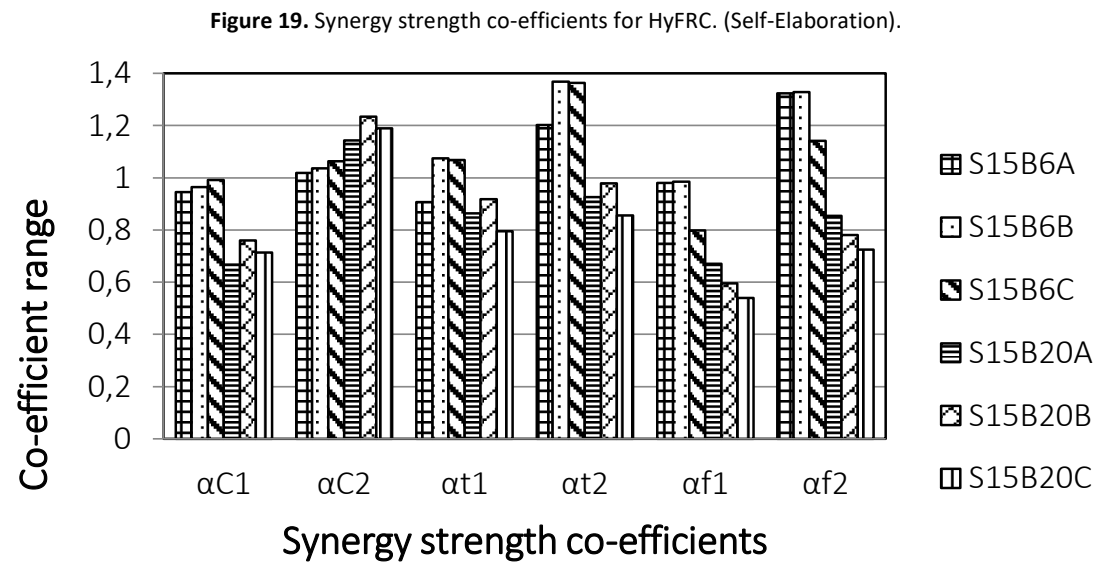

\section{Fracture properties}

The fracture parameters were determined based on RILEM 50 FMC, tabulated in Table. Fracture energy (GF) (Aydın, 2013; Foon \& Stefan, 2011; Kabay, 2014), critical stress intensity factor or fracture toughness (KIC) (Zhu, Joyce, \& Academy, 2012) and characteristic length (Ich) (Aydın, 2013) were determined. The formula for the parameters are given by,

where,

$$
G_{f}=(W+m g \delta) / A_{n e t}
$$

W - Area under the load-deflection curve

$\mathrm{m}$ - Weight of the prism

$\mathrm{g}$ - Acceleration due to gravity

$\boldsymbol{\delta}$ - ultimate deflection ( $5 \mathrm{~mm}$ )

$A_{\text {net }}-$ net area of beam cross section.

where,

$$
I_{c h}=\left(G_{f} x E_{c}\right) /\left(f_{t}^{2}\right)
$$

$\mathrm{E}_{\mathrm{c}}-$ Young's modulus

$F_{t}$ - Tensile strength

$$
K_{I C}=\sqrt{\left(G_{f} x E_{c}\right)}
$$

The softening behavior of concrete was examined from the concept of fracture energy proposed by Hillerborg et al (hillerborg, A. \& Modeer, M. 1976). Fracture energy is given by absorbed energy of the surface fractured per unit area (Bhosale et al., 2019). Figure 26 shows the load-deflection response of HFRC notched prisms for the optimum mix S15B6B which is considered to be predominant under various behavior. To compare the response of the control concrete $\mathrm{COB}, \mathrm{C} 4 \mathrm{OB}$ were recorded for fracture parameters. The integration of fibers in concrete gradually increases up to the first crack load and exhibits a softening response with excellent toughness and post cracking resistance. As 
observed from the Figure 26 the energy might be absorbed by the fibers under failure upon elongation and pull out increasing the ductility of the specimen. The two different types of fiber with different mechanical properties and aspect ratios enhanced the strength and stiffness at the micro and macro level (Bhosale et al., 2019). The coarse aggregate complemented the mixture. The control specimen was observed with a sudden load drop soon after the crack initiation. C40B behaved better whose energy absorbed per area was $1.11 \mathrm{kN} . \mathrm{mm}$ whereas COB was $0.395 \mathrm{kN} . \mathrm{mm}$ evaluated in Table 11. When the control specimens were observed from figure 23 and 24 , the propagation of cracks was minimum since the maximum load with deflection has been attained early compared to the hybrid fiber mixture.

The fracture energy of the control concrete was found to be lower than HFRC. GF of S15B6B is 17 times higher than C40B and 28 times higher than $\mathrm{COB}$. In this case, the effect of copper slag, aggregate proportion and fiber inclusion (Kabay, 2014) influences the fracture energy. The fracture energy of control specimen with copper slag C40B is 2 times higher than the control without copper slag COB. Thus the integrity of fibers with coarse aggregate and copper slag is higher in the optimum mixture. The failure of specimens took place by fiber pullout or de-bonding at ultimate load which is considered to be the most defining characteristic of concrete with increased fracture toughness (Aydın, 2013; Foon \& Stefan, 2011). The fracture toughness of HFRC is 4.5 times higher than C4OB and 6.13 times higher than COB.

The HFRC specimen expressed mild crack propagation of various branches from the crack tip and it did not break or bend at the controlled deflection. The growth of the crack tip is reduced due to the bridging action which absorbed more energy under fracture (Bhosale et al., 2019). The fibers resisted the propagation of cracks at the micro and macro scale and deflected up to $2.64 \mathrm{~mm}$ at maximum load shown in figure 25.

A material will undergo ductile fracture only when the toughness of the material is higher under fracture (Jebadurai, Tensing, Hemalatha, \& Siva, 2018). As far as Ich is concerned, as the characteristic length increases the ductile nature of the materials increases and vice versa. The index of HFRC is 6 times higher than C4OB and 7 times higher than COB.

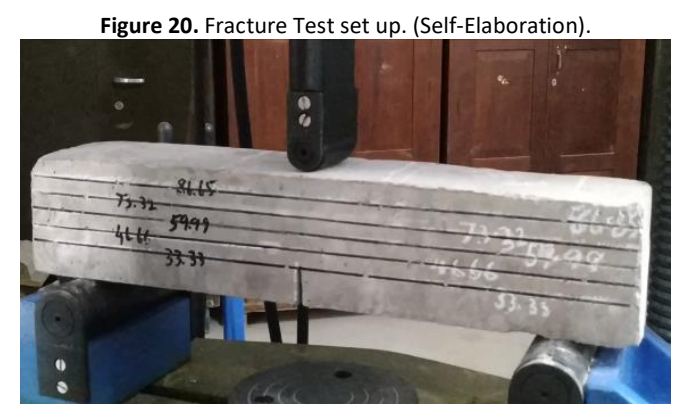

Figure 21. Crack propagation from the notch - CO mix (Grayscale image). (SelfElaboration).

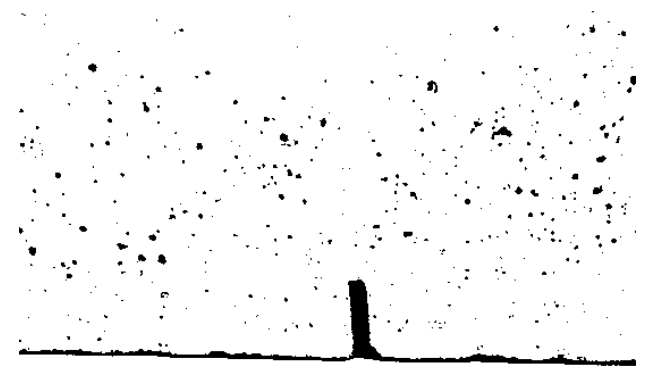

Figure 22. Crack propagation from the notch - C40 mix (Grayscale image). (SelfElaboration).

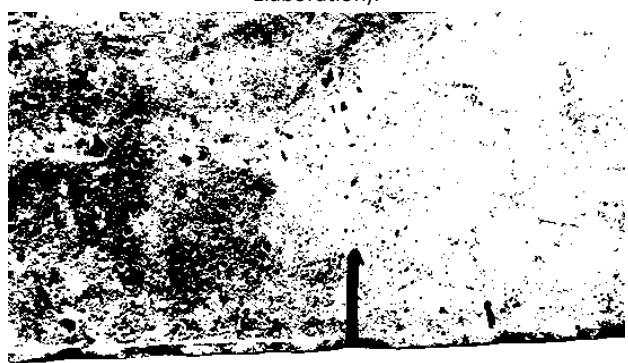

Figure 23. Crack propagation from the notch - S15B6B. (Self-Elaboration).

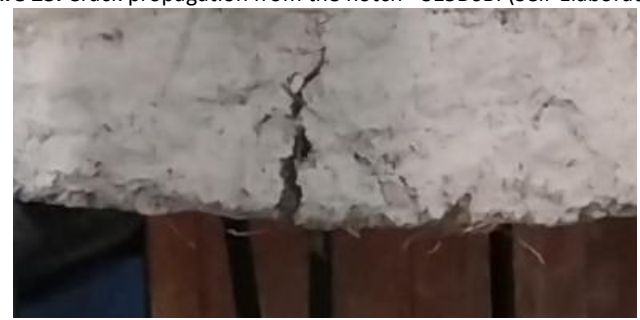


Table 9. Fracture parameters of the optimum and control mix. (Self-Elaboration).

\begin{tabular}{|c|c|c|c|c|c|c|c|c|c|c|c|c|}
\hline \multirow[b]{2}{*}{ ID } & \multicolumn{3}{|c|}{ Dimension of the specimen } & \multicolumn{2}{|c|}{ Notch details } & \multirow{2}{*}{$\begin{array}{c}\text { W } \\
(\mathrm{kN} \cdot \mathrm{mm})\end{array}$} & \multirow[b]{2}{*}{$\begin{array}{c}\Delta \\
(\mathrm{m})\end{array}$} & \multirow[b]{2}{*}{$\begin{array}{c}\text { Max. Load } \\
P_{\max }(k N)\end{array}$} & \multirow{2}{*}{$\begin{array}{l}\Delta \text { at } \\
P_{\max } \\
(\mathrm{mm})\end{array}$} & \multirow{2}{*}{$\begin{array}{c}\text { Size dependent } \\
\text { fracture energy } \\
\mathrm{G}_{\mathrm{F}}(\mathrm{N} / \mathrm{m})\end{array}$} & \multirow{2}{*}{$\begin{array}{l}\text { Stress intensity } \\
\text { factor or Fracture } \\
\text { toughness }\left(\mathrm{K}_{\mathrm{IC}}\right)\end{array}$} & \multirow{2}{*}{$\begin{array}{l}\text { Characteristic } \\
\text { length }(\mathrm{mm})\end{array}$} \\
\hline & $\mathrm{L}(\mathrm{mm})$ & $\mathrm{b}(\mathrm{mm})$ & $\mathrm{d}(\mathrm{mm})$ & $a_{0} / d$ & $\begin{array}{c}\mathrm{a}_{0}=\mathrm{d} / 3 \\
(\mathrm{~mm})\end{array}$ & & & & & & & \\
\hline $\mathrm{COB}$ & 500 & 100 & 100 & 0.33 & 33.33 & 0.395 & 0.005 & 2.07 & 0.25 & 156.32 & 56.21 & 299.16 \\
\hline $\mathrm{C} 40 \mathrm{~B}$ & 500 & 100 & 100 & 0.33 & 33.33 & 1.11 & 0.005 & 4.18 & 0.41 & 262.31 & 79.77 & 352.28 \\
\hline S15B6B & 500 & 100 & 100 & 0.33 & 33.33 & 29.35 & 0.005 & 6.67 & 2.64 & 4480.16 & 343.20 & 2145.18 \\
\hline
\end{tabular}

Figure 26. Load deflection plots for the mix CO, C40 and S15B6B (Notched prism). (Self-Elaboration).
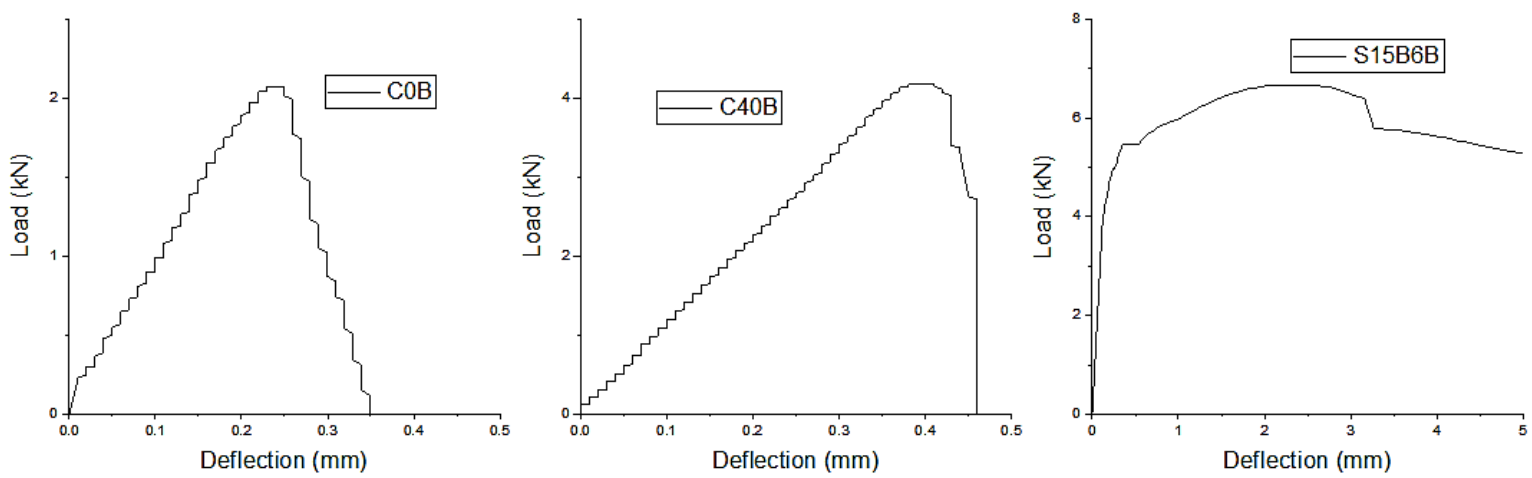

\section{Microstructural studies}

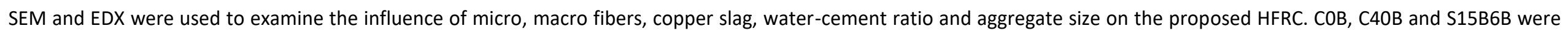
the chosen mix samples to evaluate the microstructure properties.

\section{Morphology and structure of fibers}

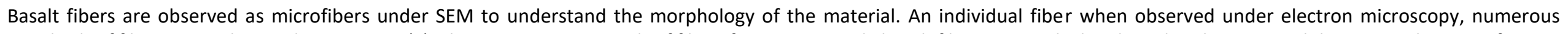

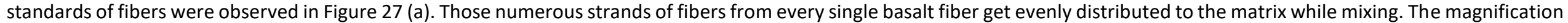

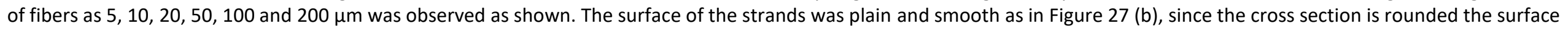

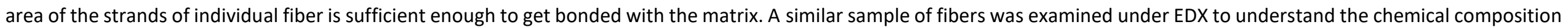

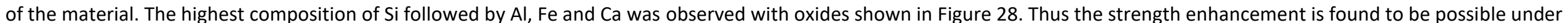
the analysis.

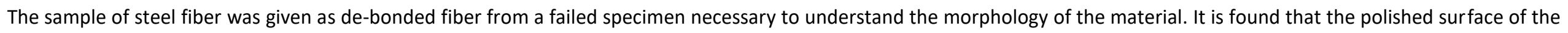

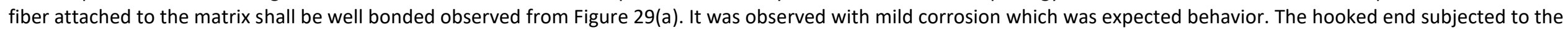


anchorage was not seen in the image, due to the length constraint of the sample. Since morphology is the prime evaluation, the length of the fiber was shortened due to the length constraints. Under the chemical composition of steel fibers, higher content of C, oxides followed by Fe and Ca were observed shown in Figure 29(b). Minimum salt deposits were identified as chlorine. As an effect of minimal corrosion, $\mathrm{C}$ and $\mathrm{CL}$ were exhibited, since the peak point of position was at the point of mild corrosion.
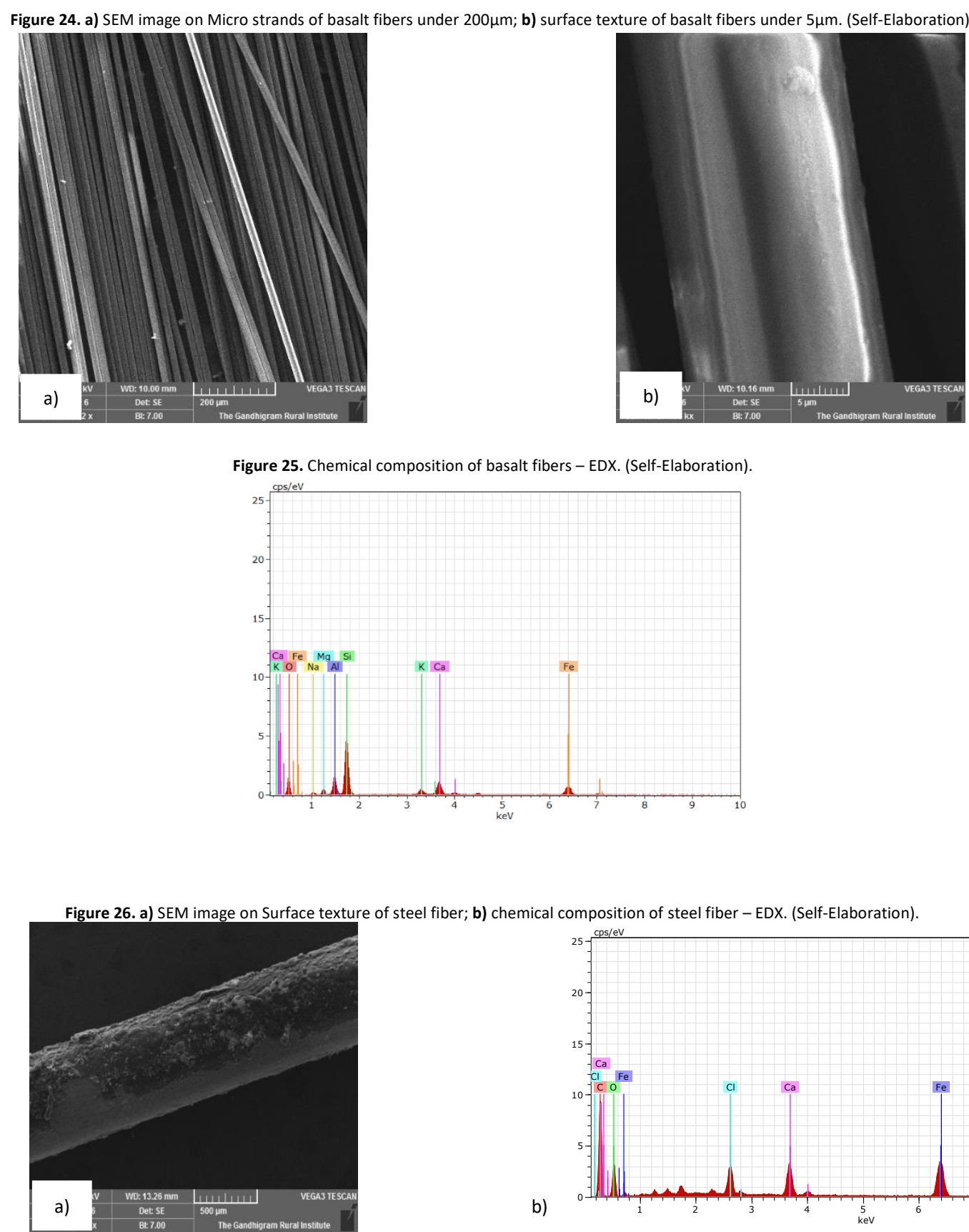

\section{Observations from the concrete sample}

$\mathrm{COB}, \mathrm{C} 40 \mathrm{~B}$ were the control mix samples without and with copper slag. S15B6B was found to be optimum from the overall performance of the mixtures. COB sample in Figure $30(\mathrm{a})$ and $(\mathrm{b})$ showcased proper bond between the matrix and the aggregate along with the formation of calcium hydrates which was ensured through EDX results in Figure 31. Similar observations are made in the mixture $\mathrm{C} 40 \mathrm{~B}$ in Figure 32 (b) and the interface bond between the aggregate and the matrix was perfectly established which is shown in Figure 32 (a). The presence of $\mathrm{Ca}, \mathrm{Al}$ and $\mathrm{Si}$ in EDX ensured the bonding and strength property of the mixture. Fe content indicated the existence of copper slag in the EDX results observed in Figure 33. 
The SEM images of aggregate matrix bonding and fiber-matrix bonding are shown in the images. The macro steel fibers resisted the crack propagation by bridging action which was not able to capture under SEM. Despite the smooth surface of basalt fibers, the bonding between the fibers and matrix was inevitably observed in Figure 34(b). A dense hydrated cement matrix was observed around basalt fiber shown in fig 35(a) (Khan, Cao, \& Ali, 2018). Under microstructure, $0.6 \%$ of volume fraction of basalt fibers was found to have dispersed numerous standards providing optimum distribution observed in Figure 34(a). In the case of $2 \%$ volume fraction, the quality of the matrix would have compromised due to the irregular distribution of fibers. Fig 35(b) exhibits a steel fiber surrounded by the formation of fibrous structure (Afroughsabet et al., 2018) as a reticular network normally known as tobermorite gel. It had the higher surface area around the fibers (Mehta \& Monteiro, 2006).

The presence of calcium and silicate hydrates were confirmed through EDX shown in Figure 36 might be due to the presence of basalt and aggregate content. Ca/Si ratio was found to be 2.5 (Richardson, 2004) and Si/Al ratio was 2.93 . Fe content denotes the existence of copper slag and steel fibers in the mixture. Minimum Carbon content with oxides was observed indicating the initiation of corrosion due to the presence of steel fiber. No detrimental/capillary voids were seen in the HFRC sample due to the adopted lower water-cement ratio of 0.35 (Mehta \& Monteiro, 2006). Also, the use of proportioned aggregate reduced elongation and enhanced optimum compaction with fibers. From the observations, it is evident that the larger amount of fibrillated network formed in the mixture fills the pores created during mixing which results in inadequate pores (Afroughsabet et al., 2018). The water retention took place from copper slag was absorbed by the basalt fiber which hydrophilic compensating the excess water circulated.
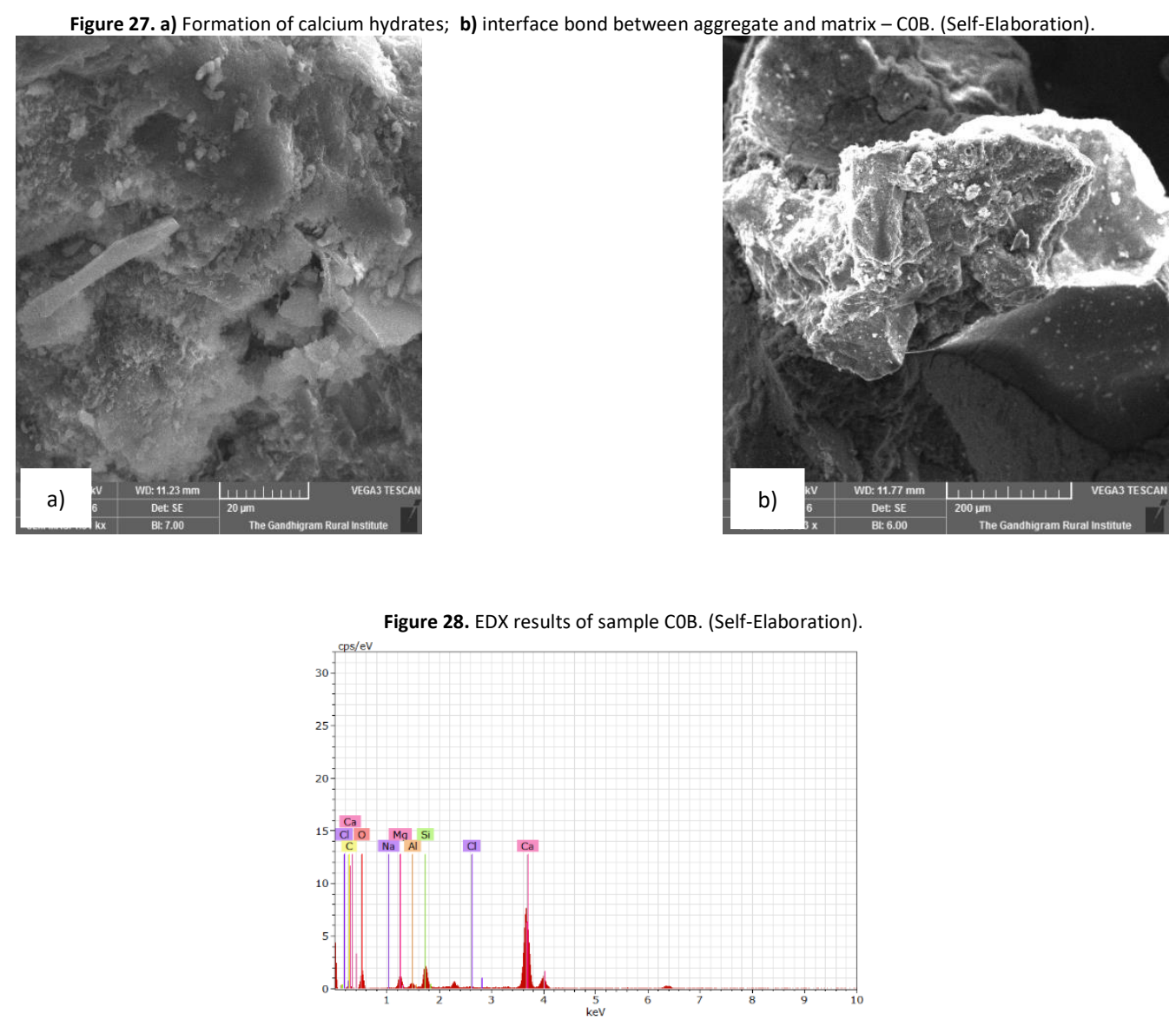
Figure 29. a) Aggregate - matrix bonding; b) calcium hydrate deposits - C4OB. (Self-Elaboration).
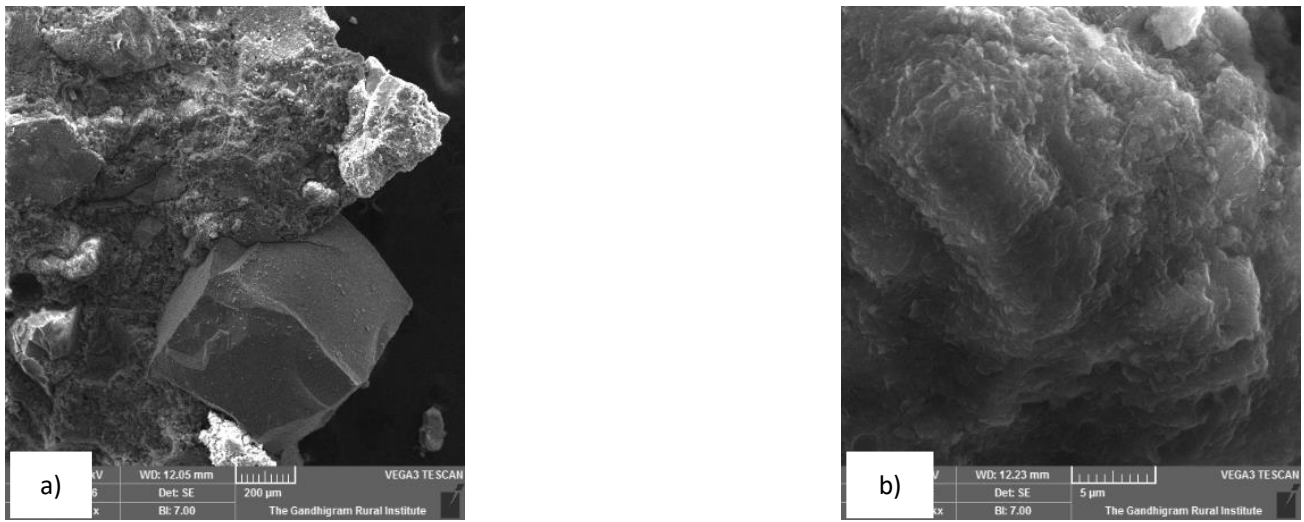

Figure 30. EDX result of sample C40B. (Self-Elaboration)

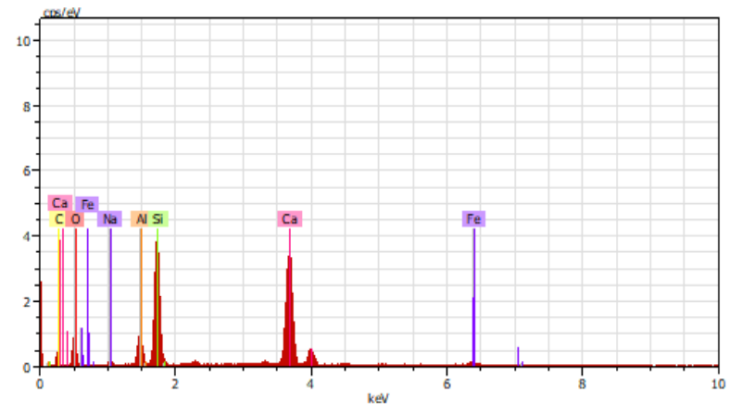

Figure 31. a) Dispersion of basalt fibers as micro strands; b) bonded fiber strands in the matrix - S15B6B. (Self-Elaboration)
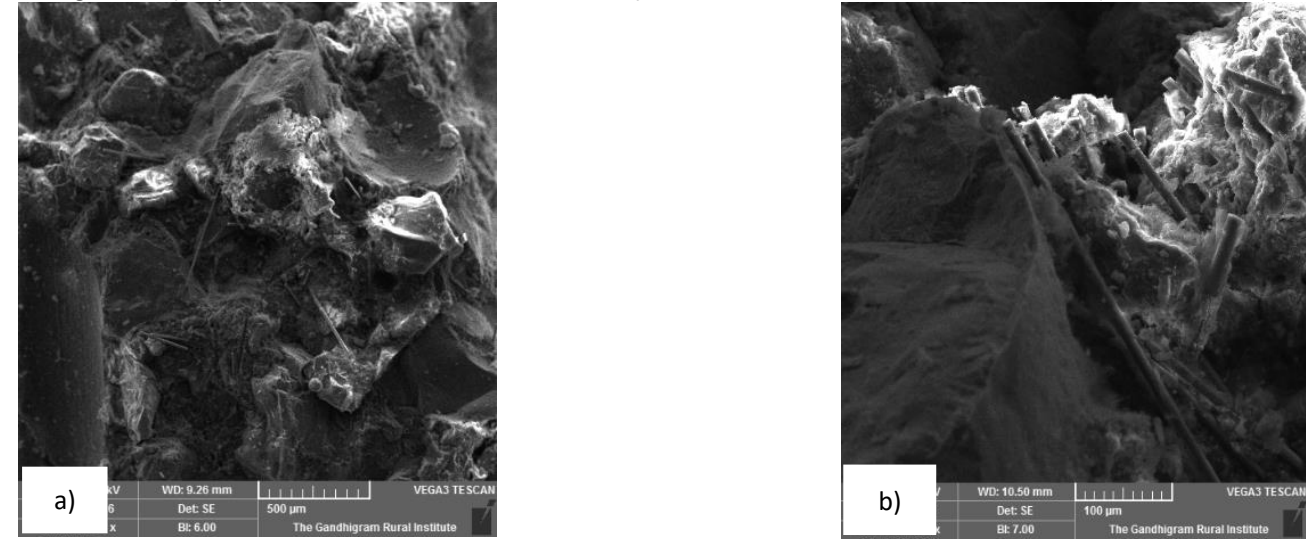

Figure 32. a) Dense hydrated matrix around basalt fiber strands; b) fibrous network around steel macro fiber. (Self-Elaboration).
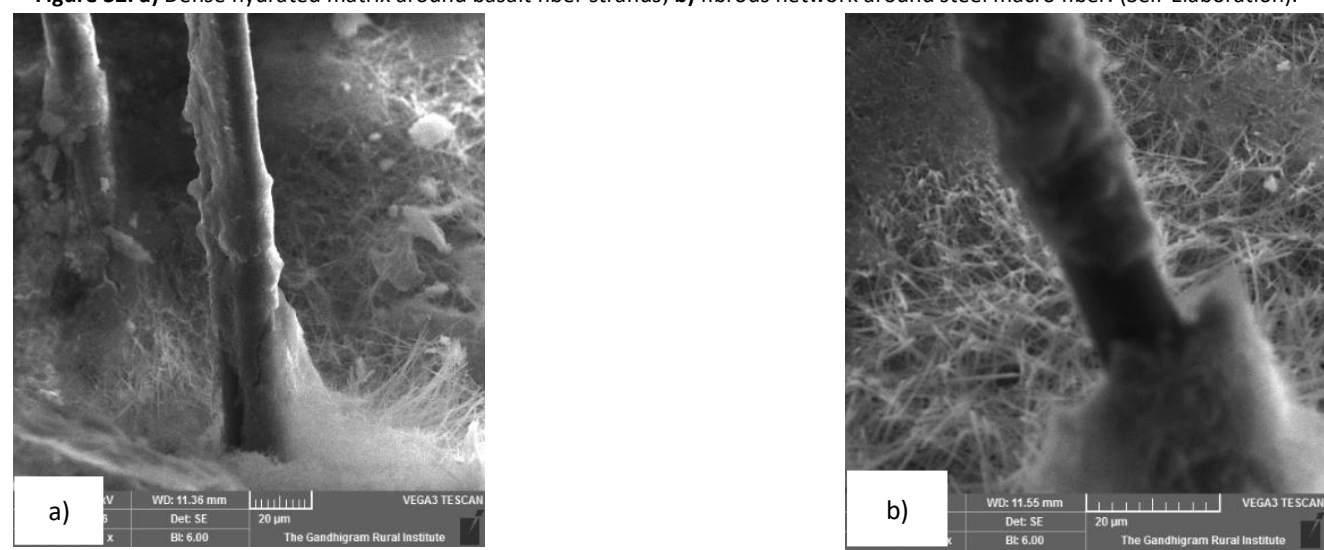


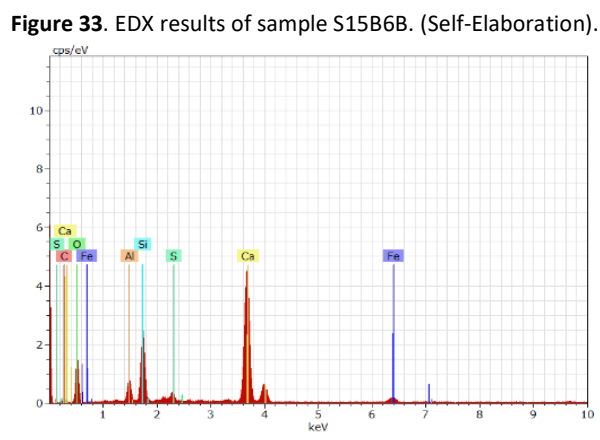

Conclusions

The laboratory study assessed the mechanical properties such as compressive strength, stress-strain data, split tensile strength, flexural strength and toughness, fracture properties and microstructural properties of Hybrid fiber reinforced concrete with metallic + nonmetallic combination of fibers. The synergy effect of the combined steel and basalt fibers with two different volume fractions $(1.5+0.6 \% \& 1.5+2 \%)$ and 3 different aggregate combinations $(A, B$ and $C)$ was evaluated. Based on the observations, the following conclusions can be drawn:

- Development of mechanical performance of concrete with the inclusion of normal strength fibers with smaller amounts along with an industrial by-product (Copper slag) provides economical production of fiber reinforced concrete. Besides, it maintained a decent workability condition despite the water-cement ratio of 0.35 by adopting various dosages of superplasticizers.

- The performance of HyFRC enhanced with the optimum volume fraction of $1.5 \%$ of steel fibers and $0.6 \%$ of basalt fibers with three different aggregate mixes. Increment of compressive strength was observed only up to $6 \%$ in C mix, Split tension as $74 \%$ in B mix and Flexural strength as $85 \%$ in B mix with respect to the control concrete with copper slag (C40). The B mix exhibited the highest toughness properties under flexure. The effect of steel and basalt fibers complement each other in the mechanical properties while the steel fiber is considered to be superior due to its geometry and physical properties than basalt fibers under various behaviors.

- The synergy effect was found to be the best under the optimum volume fraction of fibers. When the strength of mixtures was compared to the control concrete without copper slag, the increment in compression, split tension and flexure were found to be $21 \%, 128 \%$ and $250 \%$ which was remarkable. Even though, the S15B6 mixture gave predominant results at 50-50 aggregate proportion of $20+12.5 \mathrm{~mm}$, ' $\mathrm{A}$ ' mix i.e. $100 \%$ of $20 \mathrm{~mm}$ aggregate proportion found to have higher peak strain compared to other mixes due to the larger size aggregate. Thus from the observations under static loading conditions, it is suggested that the volume fraction of basalt fibers and steel fibers in copper slag concrete cannot exceed $0.6 \%$ and $1.5 \%$ as micro and macro fibers.

- Based on the results from experiments, the optimum mix was confirmed in calculating the fracture parameters and microstructural properties. In which the fracture energy, fracture toughness and the characteristic length showed predominant results from which the ductile property of the mix was ensured. The microstructural test results through SEM and EDX confirmed the existence of chemical compounds responsible for the strength and bond performance of the concrete mix S15B6B.

Acknowledgement

The authors would like to thank the Council of Scientific and Industrial Research (CSIR) for their financial support. 
Abbass, W., Khan, M. I., \& Mourad, S. (2018). Evaluation of mechanical properties of steel fiber reinforced concrete with different strengths of concrete. Construction and Building Materials, 168, 556-569. https://doi.org/10.1016/j.conbuildmat.2018.02.164

Afroughsabet, V., Geng, G., Lin, A., Biolzi, L., Ostertag, C. P., \& Monteiro, P. J. M. (2018). The influence of expansive cement on the mechanical, physical, and microstructural properties of hybrid-fiber-reinforced concrete. Cement and Concrete Composites, 96, 21-32. https://doi.org/10.1016/j.cemconcomp.2018.11.012

Al-Jabri, K. S., Al-Saidy, A. H., \& Taha, R. (2011). Effect of copper slag as a fine aggregate on the properties of cement mortars and concrete. Construction and Building Materials, 25(2), 933-938. https://doi.org/10.1016/j.conbuildmat.2010.06.090

Alex, X., \& Arunachalam, K. (2019). Flexural behavior of fiber reinforced lightweight concrete. Journal of Construction, 18(3), 536-544. https://doi.org/10.7764/RDLC.18.3.536

Aydın, S. (2013). Effects of fiber strength on fracture characteristics of normal and high strength concrete. Periodica Polytechnica Civil Engineering, 57(2), 191-200. https://doi.org/10.3311/PPci.7174

Ayub, T., \& Khan, S. U. (2017). Finite element modelling of FRC beams containing PVA and Basalt fibres: A comparative study. In AIP Conference Proceedings (Vol. 1872, No. 1, p. 020002). AIP Publishing LLC. https://doi.org/10.1063/1.4996659

Ayub, T., Shafiq, N., \& Nuruddin, M. F. (2014). Mechanical Properties of High-Performance Concrete Reinforced with Basalt Fibers. Procedia Engineering, 77, 131-139. https://doi.org/10.1016/j.proeng.2014.07.029

Banthia, N., Majdzadeh, F., Wu, J., \& Bindiganavile, V. (2014). Fiber synergy in Hybrid Fiber Reinforced Concrete ( HyFRC) in flexure and direct shear. Cement \& Concrete Composites, 48, 91-97. https://doi.org/10.1016/j.cemconcomp.2013.10.018

Bentur, A., \& Mindess, S. (2006). Fibre Reinforced Cementitious Composites. Boca Ratón, United States: Crc Press.

Bhosale, A., Rasheed, M. A., Prakash, S. S., \& Raju, G. (2019). A study on the efficiency of steel vs . synthetic vs . hybrid fibers on fracture behavior of concrete in flexure using acoustic emission. Construction and Building Materials, 199, $256-268$. https://doi.org/10.1016/j.conbuildmat.2018.12.011

Branston, J., Das, S., Kenno, S. Y., \& Taylor, C. (2016). Mechanical behaviour of basalt fibre reinforced concrete. Construction and Building Materials, 124, 878-886. https://doi.org/10.1016/j.conbuildmat.2016.08.009

Walton, P. L., \& Majumdar, A. J. (1975). Cement-based composites with mixtures of different types of fibres. Composites, 6(5), 209-216.

Cao, M., Xie, C., \& Guan, J. (2019). Fracture Behavior of Cement Mortar Reinforced by Hybrid Composite Fiber Consisting of CaCO 3 Whiskers and PVA-Steel. Composites Part A: Applied Science and Manufacturing, 120, 172-187. https://doi.org/10.1016/j.compositesa.2019.03.002

Cattaneo, S., \& Biolzi, L. (2010). Assessment of thermal damage in hybrid fiber-reinforced concrete. Journal of materials in civil engineering, 22(9), 836-845.

Chakrawarthi, V., Darmar, B., \& Elangovan, A. (2016). Copper slag concrete admixed with polypropylene fibres. Građevinar, 68(2), 95-104.

Chun, B., \& Yoo, D. (2018). Hybrid effect of macro and micro steel fibers on the pullout and tensile behaviors of ultra-high-performance concrete. Composites Part B: Engineering, 162, 344-360. https://doi.org/10.1016/j.compositesb.2018.11.026

Correal, J. F., Herrán, C. A., Carrillo, J., Reyes, J. C., \& Hermida, G. (2018). Performance of hybrid fiber-reinforced concrete for low-rise housing with thin walls. Construction and Building Materials, 185, 519-529. https://doi.org/10.1016/j.conbuildmat.2018.07.048

Dawood, E. T., Mohammad, Y. Z., Abbas, W. A., \& Mannan, M. A. (2018). Toughness, elasticity and physical properties for the evaluation of foamed concrete reinforced with hybrid fi bers, Heliyon, 4(12), e01103. https://doi.org/10.1016/j.heliyon.2018.e01103

Qu, S., \& Lin, S. (2012). Civil Engineering and Urban Planning 2012. International Conference On Civil Engineering And Urban Planning. Yantai University, Yantai, China, August 18-20, 2020.

Erden, S., \& Ho, K. (2017). 3 - Fiber reinforced composites. Fiber Technology for Fiber-Reinforced Composites. (pp. 51-79). Izmir, Turkey: Woodhead Publishing. https://doi.org/10.1016/B978-0-08-101871-2.00003-5

Lee, S. F., \& Jacobsen, S. (2011). Study of interfacial microstructure, fracture energy, compressive energy and debonding load of steel fiber-reinforced mortar. Materials and structures, 44(8), 1451-1465.

Guler, S. (2018). The effect of polyamide fibers on the strength and toughness properties of structural lightweight aggregate concrete. Construction and Building Materials, 173, 394-402. https://doi.org/10.1016/j.conbuildmat.2018.03.212

Guler, S., Yavuz, D., Korkut, F., \& Ashour, A. (2019). Strength prediction models for steel, synthetic, and hybrid fiber reinforced concretes. Structural Concrete, 20(1), 428-445. https://doi.org/10.1002/suco.201800088

Hillerborg, A., Modéer, M., \& Petersson, P. E. (1976). Analysis of crack formation and crack growth in concrete by means of fracture mechanics and finite elements. Cement and concrete research, 6(6), 773-781.

Holschemacher, K., Mueller, T., \& Ribakov, Y. (2010). Effect of steel fibres on mechanical properties of high-strength concrete. Materials and Design, 31(5), 2604-2615. https://doi.org/10.1016/j.matdes.2009.11.025

Jebadurai, S. V. S., Tensing, D., Hemalatha, G., \& Siva, R. (2018). Experimental investigation of toughness enhancement in cement mortar. International Journal of Engineering, 31(11), 1824-1829. https://doi.org/10.5829/ije.2018.31.11b.04 
Jiang, C., Fan, K., Wu, F., \& Chen, D. (2014). Experimental study on the mechanical properties and microstructure of chopped basalt fibre reinforced concrete. Materials \& Design, 58, 187-193. https://doi.org/10.1016/J.MATDES.2014.01.056

Jiao, H., Wu, Y., Chen, X., \& Yang, Y. (2019). Flexural toughness of basalt fibre-reinforced shotcrete and industrial-scale testing. Advances in Materials Science and Engineering, Volume 2019, 1-8. https://doi.org/10.1155/2019/6568057

John, V. J., \& Dharmar, B. (2020). Effect of steel macro fibers on engineering properties of copperslag-concrete. Structural Concrete, 21(2), 689-702. https://doi.org/10.1002/suco.201900109

Kabay, N. (2014). Abrasion resistance and fracture energy of concretes with basalt fiber. Construction and Building Materials, 50, 95-101. https://doi.org/10.1016/j.conbuildmat.2013.09.040

Karahan, O. (2020). Resistance of polypropylene fibered mortar to elevated temperature under different cooling regimes. Journal of Construction, 18(2), 386-397. https://doi.org/10.7764/RDLC.18.2.386

Khan, M., Cao, M., \& Ali, M. (2018). Effect of basalt fibers on mechanical properties of calcium carbonate whisker-steel fiber reinforced concrete. Construction and Building Materials, 192, 742-753. https://doi.org/10.1016/j.conbuildmat.2018.10.159

Kim, D., Naaman, A., Eltawil, S. (2008). Comparative Flexural Behavior of Four Fiber Reinforced Cementitious Composites. Cement and Concrete Composites, 30(10), 917-928.

Kizilkanat, A. B., Kabay, N., Akyüncü, V., Chowdhury, S., \& Akça, A. H. (2015). Mechanical properties and fracture behavior of basalt and glass fiber reinforced concrete: An experimental study. Construction \& Building Materials, 100, 218-224. https://doi.org/10.1016/j.conbuildmat.2015.10.006

Koniki, S., \& Prasad, D. R. (2019). Influence of hybrid fibres on strength and stress-strain behaviour of concrete under uni-axial stresses. Construction and Building Materials, 207, 238-248. https://doi.org/10.1016/j.conbuildmat.2019.02.113

Dash, M. K., Patro, S. K., \& Rath, A. K. (2016). Sustainable use of industrial-waste as partial replacement of fine aggregate for preparation of concreteA review. International Journal of Sustainable Built Environment, 5(2), 484-516.

Li, B., Chi, Y., Xu, L., Shi, Y., \& Li, C. (2018). Experimental investigation on the flexural behavior of steel-polypropylene hybrid fiber reinforced concrete. Construction and Building Materials, 191, 80-94. https://doi.org/10.1016/j.conbuildmat.2018.09.202

Mehta, P. K., \& Monteiro, P. J. (2014). Concrete: microstructure, properties, and materials. McGraw-Hill Education.

Mobasher, B., Yao, Y., \& Soranakom, C. (2015). Analytical solutions for flexural design of hybrid steel fiber reinforced concrete beams. Engineering Structures, 100, 164-177. https://doi.org/10.1016/j.engstruct.2015.06.006

Murari, K., Siddique, R., \& Jain, K. K. (2014). Use of waste copper slag, a sustainable material. Journal of Material Cycles and Waste Management, 17(1), 13-26. https://doi.org/10.1007/s10163-014-0254-x

Nataraja, M. C., Dhang, N., \& Gupta, A. P. (1999). Stress-strain curves for steel-fiber reinforced concrete under compression. Cement and concrete composites, 21(5-6), 383-390.

Qian, C., \& Stroeven, P. (2000). Fracture properties of concrete reinforced with steel-polypropylene hybrid fibres. Cement and Concrete Composites, 22(5), 343-351.

Qian, C. X., \& Stroeven, P. (2000). Development of hybrid polypropylene-steel fibre-reinforced concrete. Cement and Concrete Research, 30(1), 6369. https://doi.org/10.1016/S0008-8846(99)00202-1

Tixier, R., Devaguptapu, R., \& Mobasher, B. (1997). The effect of copper slag on the hydration and mechanical properties of cementitious mixtures. Cement and Concrete Research, 27(10), 1569-1580.

Richardson, I. G. (2004). Tobermorite/jennite-and tobermorite/calcium hydroxide-based models for the structure of CSH: applicability to hardened pastes of tricalcium silicate, $\beta$-dicalcium silicate, Portland cement, and blends of Portland cement with blast-furnace slag, metakaolin, or silica fume. Cement and Concrete Research, 34(9), 1733-1777. https://doi.org/10.1016/j.cemconres.2004.05.034

Sahoo, D. R., Solanki, A., \& Kumar, A. (2015). Influence of steel and polypropylene fibers on flexural behavior of RC beams. Journal of Materials in Civil Engineering, 27(8), 04014232. https://doi.org/10.1061/(ASCE)MT.1943-5533.0001193.

Saidani, M., Saraireh, D., \& Gerges, M. (2016). Behaviour of different types of fibre reinforced concrete without admixture. Engineering Structures, 113, 328-334. https://doi.org/10.1016/j.engstruct.2016.01.041

Shafiq, N., Ayub, T., \& Ullah, S. (2016). Investigating the performance of PVA and basalt fibre reinforced beams subjected to flexural action. Composite Structures, 153, 30-41. https://doi.org/10.1016/j.compstruct.2016.06.008

Shi, C., Meyer, C., \& Behnood, A. (2008). Utilization of copper slag in cement and concrete. Resources, Conservation and recycling, 52(10), 1115-1120. https://doi.org/10.1016/j.resconrec.2008.06.008

Jalasutram, S., Sahoo, D., \& V. M. (2016). Experimental investigation on mechanical properties of basalt fibre-reinforced concrete. Structural Concrete, 18(2), 292-302. https://doi.org/10.1002/suco.201500216

Sun, L., Hao, Q., Zhao, J., Wu, D., \& Yang, F. (2018). Stress strain behavior of hybrid steel-PVA fiber reinforced cementitious composites under uniaxial compression. Construction and Building Materials, 188, 349-360. https://doi.org/10.1016/j.conbuildmat.2018.08.128

Jamshaid, H., \& Mishra, R. (2016). A green material from rock: basalt fiber-a review. The Journal of The Textile Institute, 107(7), 923-937. https://doi.org/10.1080/00405000.2015.1071940 
Teng, S., Afroughsabet, V., \& Ostertag, C. P. (2018). Flexural behavior and durability properties of high performance hybrid-fiber-reinforced concrete. Construction and Building Materials, 182, 504-515. https://doi.org/10.1016/j.conbuildmat.2018.06.158

Wang, D., Ju, Y., Shen, H., \& Xu, L. (2019). Mechanical properties of high performance concrete reinforced with basalt fiber and polypropylene fiber. Construction and Building Materials, 197, 464-473. https://doi.org/10.1016/j.conbuildmat.2018.11.181

Wu, W., Zhang, W., \& Ma, G. (2010). Optimum content of copper slag as a fine aggregate in high strength concrete. Materials and Design, 31(6), 2878-2883. https://doi.org/10.1016/j.matdes.2009.12.037

Yap, S. P., Alengaram, U. J., \& Jumaat, M. Z. (2016). The effect of aspect ratio and volume fraction on mechanical properties of steel fibre-reinforced oil palm shell concrete. Journal of Civil Engineering and Management, 22(2), 168-177. https://doi.org/10.3846/13923730.2014.897970

Yurtseven, A. E., Yaman, I. O., \& Tokyay, M. U. S. T. A. F. A. (2006). Mechanical properties of hybrid fiber reinforced concrete. In Measuring, Monitoring and Modeling Concrete Properties (pp. 207-214). Springer, Dordrecht.

Zhang, H., Wang, L., Bai, L., Addae, M., \& Neupane, A. (2019). Research on the impact response and model of hybrid basalt-macro synthetic polypropylene fiber reinforced concrete. Construction and Building Materials, 204, 303-316. https://doi.org/10.1016/j.conbuildmat.2019.01.201

Zhang, L., Liu, J., Liu, J., Zhang, Q., \& Han, F. (2018). Effect of steel fiber on flexural toughness and fracture mechanics behavior of ultrahighperformance concrete with coarse aggregate. Journal of Materials in Civil Engineering, 30(12), 04018323. https://doi.org/10.1061/(ASCE)MT.1943-5533.0002519.

Zhu, X. K., \& Joyce, J. A. (2012). Review of fracture toughness (G, K, J, CTOD, CTOA) testing and standardization. Engineering Fracture Mechanics, 85, 1-46. https://doi.org/10.1016/j.engfracmech.2012.02.001 